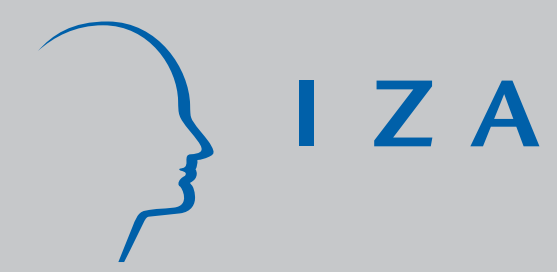

IZA DP No. 1908

Labour Supply and Childcare for British Mothers in Two-Parent Families: A Structural Approach

Antonia Parera-Nicolau

Karen Mumford

December 2005 


\title{
Labour Supply and Childcare for British Mothers in Two-Parent Families: A Structural Approach
}

\author{
Antonia Parera-Nicolau \\ Universitat de les IIles Balears \\ Karen Mumford \\ University of York \\ and IZA Bonn
}

Discussion Paper No. 1908

December 2005

IZA

P.O. Box 7240

53072 Bonn

Germany

Phone: +49-228-3894-0

Fax: +49-228-3894-180

Email: iza@iza.org

Any opinions expressed here are those of the author(s) and not those of the institute. Research disseminated by IZA may include views on policy, but the institute itself takes no institutional policy positions.

The Institute for the Study of Labor (IZA) in Bonn is a local and virtual international research center and a place of communication between science, politics and business. IZA is an independent nonprofit company supported by Deutsche Post World Net. The center is associated with the University of Bonn and offers a stimulating research environment through its research networks, research support, and visitors and doctoral programs. IZA engages in (i) original and internationally competitive research in all fields of labor economics, (ii) development of policy concepts, and (iii) dissemination of research results and concepts to the interested public.

IZA Discussion Papers often represent preliminary work and are circulated to encourage discussion. Citation of such a paper should account for its provisional character. A revised version may be available directly from the author. 
IZA Discussion Paper No. 1908

December 2005

\section{ABSTRACT}

\section{Labour Supply and Childcare for British Mothers in Two-Parent Families: A Structural Approach ${ }^{*}$}

We develop and estimate a structural model of labour supply for British two parent families, taking explicit account of the importance of childcare related variables. We find working mothers do not increase their working hours when hourly wages increase, indeed, they are more likely to reduce their hours. The major inducement for working mothers to increase their working hours, that we find, is the provision of high quality formal childcare. Implying that government policy aiming at increasing working hours amongst British mothers of pre-school children may need to focus on the quality as well as the quantity of formal child care that is available.

JEL Classification: J2, J3, J80

Keywords: $\quad$ mothers, Britain, childcare, parents labour supply

Corresponding author:

Karen Mumford

Department of Economics and Related Studies

University of York

York YO10 5DD

United Kingdom

Email: kam9@york.ac.uk

\footnotetext{
* The authors are grateful for helpful comments and advice from Alan Duncan, Mark Killingsworth, Roberto León-González, Peter N. Smith and participants at the IZA/SOLE Transatlantic Meeting of Labor Economists 2005. We are also grateful to Alan Duncan for providing initial coding used in estimation. The views expressed in this paper do not necessarily reflect those of the authors' employing bodies. Responsibility for any mistakes or omissions is entirely our own.
} 


\section{Introduction}

"The Government's vision is of a childcare system where: parents are better supported in the choices they make about their work and family responsibilities; childcare is available to all families and is flexible to meet their circumstances; childcare services are among the best quality in the world; and all families are able to afford high quality childcare services that are appropriate for their needs...Availability of childcare plays an important role in tackling disadvantage and child poverty, and supporting social mobility and equality of opportunity." (HM Treasury, 2004; page 5).

The incorporation of women into the labour force has brought to light, in developed countries, the importance of introducing social policies reconciling work and family life. Pressures for the introduction of family-friendly work practices in many countries and organizations are coming from a range of directions. In the United Kingdom and United States, for example, changes in the labor supply of women and the greater sharing of household work across parents (Gershuny, 2003) have led to an increased demand for family-friendly, work life balance, practices from diverse workers (male and female across the full socio-economic spectrum). The European Union also continues to press Member States to introduce legislation and foster policies which aim to reconcile work and family life (OJL, 2003). These efforts are intended to promote not only gender equality in the workplace but also greater quality care for children and dependents.

Moreover, many developed countries have actively linked welfare programmes to working, especially since the latter part of the 1990s (Blank, 2001; Blundell et al., 2000; Blundell and Hoynes, 2004; Elwood, 2000; Meyer and Rosenbaum, 2001). Questions abound, however, as to whether these welfare-to-work programmes will be effective at lowering poverty, since helping parents to find better jobs through training and search assistance will be of little long term benefit if constraints such as childcare cannot be catered for (Budd and Mumford, 2004; Metcalf, 1990).

As a consequence, the British Government has adopted a multi-pronged approach to encouraging family-friendly work environments which include the National Childcare Strategy, extended maternity and paternity entitlements, the minimum wage, the New Deal for Lone Parents, the Working Families Tax Credit; and the new Sure Start childcare program. There have been, however, very few papers exploring the relationship between parents' labour supply and the availability of childcare in Britain (see Blundell and Macurdy, 1999; Duncan et al, 2001; Chevalier and Viitanen, 2002). The aim of this paper is to help to fill this gap in the literature.

This paper develops and estimates a structural model of family labour supply in Britain based on the unitary family framework model (Blundell and Macurdy, 1999). Moreover, the model estimated takes explicit account of childcare-related 
issues. By being able to model the labour supply decision of both parents, and not only the mother's, the estimation of a unitary family framework model is a development over the simpler male-oriented models ${ }^{1}$. For example, with the exception of Chiuri (1998), the other relevant studies in this area take the labour supply decision of the father as given and assume that only the mother's choice is affected by childcare issues (such as price and availability). Blundell et al. (1999) model the household labour supply decision of a two-person household considering childcare variables, but restrict the male partner to a simple participation/non-participation choice.

The unitary family framework explicitly accounts for the possibility of the family considering non-parental childcare as a good in itself and not only as a tool to allow for participation in the labour market. Thus, this model allows for the possibility of observing a family using childcare for more hours than the number of hours the parents are working. With the exceptions of Duncan and Giles (1994) and Chiuri (1998), existing studies do not address the possibility of observing a non-working mother using non-parental childcare and, therefore, they present estimates of the labour supply elasticity to the price of formal childcare which are conditional on the mother working. It is not unusual, however, for children to be in formal childcare for some hours when a parent is not working. The 1991/92 General Household Survey (GHS92) shows that British families with non-working mothers consume seven hours of childcare per week on average, and that nearly 30 per cent pay for this childcare. The ability to address this empirical reality is a clear gain in the model's capacity to explain observed behaviour.

In the process, we provide structural estimates of this model which will prove useful in microsimulation exercises (of the impacts of family policies not only on the parents' labour supply decision but also on childcare take-up decisions) and in policy-related decision making. There have been other papers which have estimated structural parameters for this model, but they either only modelled the mother's labour supply decision (Michalopoulos et al. (1992) and Ribar (1995)) and/or did not consider childcare take-up among their arguments (Blundell et al.,1999).

The paper is organized as follows: section 1 describes the theoretical framework underlying the family's decision process; section 2 discusses the data set used; section 3 considers econometric specification; initial results are presented in section 4; modelling the participation decision is addressed in section 5; further results are presented in section 6 ; and section 7 concludes.

\footnotetext{
${ }^{1}$ The unitary family framework also encounters limitations which are well documented in the literature (see Blundell and McCurdy, 1999).
} 


\section{The theoretical approach}

We adopt the unitary family framework (Blundell and Macurdy, 1999) throughout this paper. Family members' utilities are represented by a unique utility function whose arguments are each family member's leisure and the family's consumption. The budget constraint pools together all the family's income. The sharing of income among the family members does not influence the family's final choice of the argument levels.

Family members are assumed to make choices regarding consumption of market goods other than childcare $(C)$, childcare quality $(Q)$, and leisure $(L)$. in such a way as to maximize their utility $U$ subject to a series of constraints.

$$
\begin{aligned}
& \max U=U\left(C, L_{M}, L_{F}, Q\right) \\
& \text { s.t. } \\
& T=L_{M}+H_{M}+K_{M} \quad \text { (1.1. mother's time constraint) } \\
& T=L_{F}+H_{F} \quad \text { (1.2. father's time constraint) } \\
& Q=Q\left(K_{M}, F, I ; Z\right) \quad \text { (1.3. child care quality (per child)) } \\
& C=\sum_{i=M, F} w_{i} \cdot H_{i}+v-P_{F} \cdot F \quad \text { (1.4. family budget constraint) } \\
& T=K_{M}+F+I \quad \text { (1.5. child's time constraint) } \\
& H_{M} \leq F+I \quad \text { (1.6. minimum child care requirement.) }
\end{aligned}
$$

Where the subscripts $M$ and $F$ represent mother and father respectively; total time $(T)$ is shared between working hours $(H)$, leisure time $(L)$ and time spent looking after the children by a parent $(K) ;(F)$ is childcare provided in the market for which the family has to pay (the number of hours of formal childcare that the family uses); $(I)$ is childcare provided for free by friends or relatives; $(Z)$ represents the set of family characteristics thought to influence childcare quality and/or the family's perception of childcare quality; $\left(w_{M}\right)$ is the mother's hourly wage; $\left(w_{F}\right)$ is the father's hourly wage; $(v)$ is the family's unearned income; and $\left(P_{F}\right)$ is the hourly price of formal childcare.

Notice that the father's time is only spent working or enjoying leisure time, in other words, the father does not spend time caring for the children. The 1991/92 General Household Survey (GHS92, discussed in section 2 below) does not distinguish whether the children are looked after by the mother or by the father, and so we have assumed that all childcare is carried out by the mother. 
There is an unfortunate loss of generality imposed by this assumption. Nevertheless, the model is still an advance over those used in the earlier studies (for example, the father's labour supply is not taken as given but it is determined by the model itself).

We also assume that if informal childcare $(I)$ is available, the family will use it (subject to a minimum quality requirement). The number of hours of informal childcare used by the family is treated as a fixed parameter, which only appears in the child's time constraint and in the minimum childcare requirement. No assumption is made as to whether the quality of childcare purchased in the market is less than, equal to, or greater than the quality of childcare provided by the mother. The expression for the quality of childcare actually used is:

$$
Q=Q\left(K_{M}, F ; Z\right)
$$

The budget constraint limits the family's consumption in the usual way. The child's time constraint indicates that the time the child is looked after is equal to the time the mother is looking after her/him plus the number of hours $\mathrm{s} /$ he is looked after by somebody else (either in formal childcare $(F)$ or in informal childcare $(I)$ ). This constraint rules out the possibility that the family leaves their children on their own. Finally, the minimum childcare requirement states that the child is looked after by someone else at least during the time the mother is working. This inequality restriction allows us to consider the use of non-parental care by non-working mothers and, in general, to consider formal childcare as a good in itself and not only as a means to facilitate employment. This expression also restricts the mother's leisure time to be non-negative.

In order to understand how the family chooses between leisure, consumption and childcare purchase, we solve the utility maximization problem. The exogenous determinants are the price of childcare; the wage rates of the parents; the family's non-labour income; and demographic characteristics of the family that may be related to their tastes. The maximization problem can be expressed as:

$$
\begin{gathered}
\operatorname{Max} \mathbf{U}=U\left(H_{M}, H_{F}, F\right)= \\
U\left(\sum_{i=M, F} w_{i} \cdot H_{i}+v-P_{F} \cdot F, Q(T-F+I, F), F+I-H_{M}, T-H_{F}\right) \\
\text { s.t. } \\
H_{M} \leq F+I
\end{gathered}
$$

The first order conditions (F.O.C.) of this maximization problem are:

$$
\text { (aa.1) } \frac{\partial U}{\partial H_{M}}=0 \Longrightarrow \frac{\partial U}{\partial C} \cdot \frac{\partial C}{\partial H_{M}}+\frac{\partial U}{\partial L_{M}} \cdot \frac{\partial L_{M}}{\partial H_{M}}-\lambda=0
$$




$$
\begin{gathered}
(a a .2) \frac{\partial U}{\partial H_{F}}=0 \Longrightarrow \frac{\partial U}{\partial C} \cdot \frac{\partial C}{\partial H_{F}}+\frac{\partial U}{\partial L_{F}} \cdot \frac{\partial L_{F}}{\partial H_{F}}=0 \\
(a a .3) \frac{\partial U}{\partial F}=0 \Longrightarrow \frac{\partial U}{\partial C} \cdot \frac{\partial C}{\partial F}+\frac{\partial U}{\partial Q} \cdot \frac{\partial Q}{\partial K_{M}} \cdot \frac{\partial K_{M}}{\partial F}+\frac{\partial U}{\partial Q} \cdot \frac{\partial Q}{\partial F}+\frac{\partial U}{\partial L_{M}} \cdot \frac{\partial L_{M}}{\partial F}+\lambda=0 \\
\left(\text { aa.4) }\left[H_{M}-(F+I)\right] \cdot \lambda=0\right. \\
\text { (aa.5) } H_{M}-(F+I) \leq 0 \\
\text { (aa.6) } \lambda \geq 0
\end{gathered}
$$

Where: $\frac{\partial C}{\partial H_{M}}=w_{M} ; \frac{\partial L_{M}}{\partial H_{M}}=-1 ; \frac{\partial C}{\partial H_{F}}=w_{F} ; \frac{\partial L_{F}}{\partial H_{F}}=-1 ; \frac{\partial C}{\partial F}=-P_{F} ; \frac{\partial K_{M}}{\partial F}=$ $-1 ; \frac{\partial L_{M}}{\partial F}=1 \quad$ and $\lambda$ is the shadow price of an extra hour of market childcare

at the optimum, that is:

$$
\lambda=\frac{\partial U\left(H_{M}^{*}, H_{F}^{*}, F^{*}\right)}{\partial F}
$$

Substituting these expressions into the F.O.C., we obtain:

$$
\begin{gathered}
\frac{\partial U}{\partial H_{M}}=0 \Longrightarrow \frac{\partial U}{\partial C} \cdot w_{M}-\frac{\partial U}{\partial L_{M}}-\lambda=0 \\
\frac{\partial U}{\partial H_{F}}=0 \Longrightarrow \frac{\partial U}{\partial C} \cdot w_{F}-\frac{\partial U}{\partial L_{F}}=0 \\
\frac{\partial U}{\partial F}=0 \Longrightarrow \frac{\partial U}{\partial L_{M}}+\left(\frac{\partial U}{\partial Q} \cdot \frac{\partial Q}{\partial F}\right)-\left(\frac{\partial U}{\partial Q} \cdot \frac{\partial Q}{\partial K_{M}}\right)-\frac{\partial U}{\partial C} \cdot P_{F}+\lambda=0 \\
{\left[H_{M}-(F+I)\right] \cdot \lambda=0} \\
H_{M}-(F+I) \leq 0 \\
\lambda \geq 0
\end{gathered}
$$

The last three F.O.C. state that if the inequality constraint $H_{M}-(F+I) \leq 0$ is binding $(=0)$ then $\lambda>0$. If it is not binding $(<0)$, then $\lambda=0$. Since the trade-offs implicit in the F.O.C. are different for the case in which the inequality constraint is binding than for the case in which it is not binding, the analysis is now presented for both cases separately. 
1.1 Case a: $H_{M}<F+I \quad(\Longrightarrow \lambda=0)$

The F.O.C. are:

$$
\begin{gathered}
\frac{\partial U}{\partial H_{M}}=0 \Longrightarrow \frac{\partial U}{\partial C} \cdot w_{M}-\frac{\partial U}{\partial L_{M}}=0 \\
\frac{\partial U}{\partial H_{F}}=0 \Longrightarrow \frac{\partial U}{\partial C} \cdot w_{F}-\frac{\partial U}{\partial L_{F}}=0 \\
\frac{\partial U}{\partial F}=0 \Longrightarrow \frac{\partial U}{\partial L_{M}}+\left(\frac{\partial U}{\partial Q} \cdot \frac{\partial Q}{\partial F}\right)-\left(\frac{\partial U}{\partial Q} \cdot \frac{\partial Q}{\partial K_{M}}\right)-\frac{\partial U}{\partial C} \cdot P_{F}=0
\end{gathered}
$$

The first F.O.C. (equation a.1) indicates that for those women participating in

the labour market, the market wage is expected to equal the shadow value of their leisure time $\left(\frac{\frac{\partial U}{\partial L_{M}}}{\frac{\partial U}{\partial C}}\right)$. Rearranging $(a .1)$, the expression for the mother's reservation wage is obtained:

$$
w_{M_{o}}=\left.\frac{\frac{\partial U}{\partial L_{M}}}{\frac{\partial U}{\partial C}}\right|_{H_{M}=0}
$$

The reservation wage is the wage rate at which an individual is indifferent between working and not working. A fall in the reservation wage reflects an increased willingness to enter the labour market, whilst a rise in the reservation wage indicates a decreased likelihood of participation. The model predicts that the likelihood of the mother's participation in the labour market is unambiguously increasing with the family's marginal utility of consumption, whereas it decreases with the family's marginal utility of the mother's leisure (the mother's likelihood to enter the labour market is lower the higher the shadow value of her leisure time). In addition, if it is assumed that the family's utility function is strictly concave in consumption, then the mother's reservation wage increases with non-labour income. These results are intuitive. Neoclassical labour economic theory predicts that individuals who have strong preferences for leisure or high levels of non-labour income will be less attracted to the labour market (Killingsworth,1983). Conversely, strong preferences for consumption should encourage labour force participation. The second F.O.C. (equation $a .2$ ) is analogous to (a.1) for the father's likelihood of participation.

The model provides additional information on the mother's optimum number of working hours. From the third F.O.C. (a.3), an expression for the marginal utility of the mother's leisure at the optimum is obtained:

$$
\frac{\partial U}{\partial L_{M}}=\frac{\partial U}{\partial C} \cdot P_{F}+\left[\left(\frac{\partial U}{\partial Q} \cdot \frac{\partial Q}{\partial K_{M}}\right)-\left(\frac{\partial U}{\partial Q} \cdot \frac{\partial Q}{\partial F}\right)\right]
$$


When the family decides on the optimum number of the mother's leisure hours, they take into account the existing trade-off between the mother's leisure time and the family's formal childcare take-up. At the optimum, the marginal utility of the mother's leisure is equal to its marginal cost. This marginal cost is given by the sum of the marginal disutility of a decrease in the family's consumption (equal to the price of an extra hour of formal childcare), and the decrease (or increase) in utility due to the substitution of an hour of mother care for formal care ${ }^{2}$. Notice that the family does not face this trade-off when deciding on the father's optimal amount of working hours.

Those families buying childcare in the market will increase the number of hours of this care until the net marginal benefit of an extra hour of formal childcare equals the net marginal benefit of an extra hour of maternal childcare. The net marginal benefit derived from using formal childcare is $\left(\frac{\partial U}{\partial Q} \cdot \frac{\partial Q}{\partial F}\right)-$ $\left(P_{F} \cdot \frac{\partial U}{\partial C}\right)$. An extra hour of formal childcare increases (decreases) the family's utility by increasing (decreasing) the quality of the child (or childcare). This increase (decrease) in family's utility constitutes the marginal benefit (cost) of formal care. The marginal cost of paid care is the decrease in utility induced by the reduction in consumption as a consequence of paying $P_{F}$ for an extra unit of care.

The net marginal benefit of using an extra hour of maternal childcare is given by $\left[\left(\frac{\partial U}{\partial Q} \cdot \frac{\partial Q}{\partial K_{M}}\right)-\frac{\partial U}{\partial L_{M}}\right]$. The marginal benefit (cost) of an extra hour of maternal childcare is $\left(\frac{\partial U}{\partial Q} \cdot \frac{\partial Q}{\partial K_{M}}\right)$, which is the marginal contribution to childcare quality of an extra hour of mother's care. The marginal cost is $\frac{\partial U}{\partial L_{M}}$, which is the decrease in family's utility as consequence of the mother's decrease in pure leisure.

Manipulating (a.3), an expression for the reservation marginal cost of formal care is obtained:

$$
P_{F_{0}}=\left.\frac{\frac{\partial U}{\partial Q}}{\frac{\partial U}{\partial C}} \cdot\left(\frac{\partial Q}{\partial F}-\frac{\partial Q}{\partial K_{M}}\right)\right|_{F=0}+\left.\frac{\frac{\partial U}{\partial L_{M}}}{\frac{\partial U}{\partial C}}\right|_{F=0 .}
$$

The concept is similar to that of a reservation wage, except that the reservation marginal cost represents a ceiling rather than a floor. The likelihood of using paid care moves in the same direction as the level of the reservation marginal cost. Again, these results conform with neoclassical theory's standard results as

\footnotetext{
${ }^{2}$ This increase or decrease in utility is via quality, as shown in the expression for $\frac{\partial U}{\partial L_{M}}$.
} 
the likelihood of formal childcare take-up increases with non-labour and total income and with the marginal utility of care quality. This likelihood is higher the higher the marginal contribution to childcare quality of formal childcare relative to the mother's care contribution. Families are less likely to use formal care if the quality of other types of care is high; if preferences for consumption are strong; and the higher is the hourly price of formal childcare per unit of quality.

In order to examine the interactions between the choice variables, F.O.C. (a.1) and F.O.C. (a.3) are combined to obtain the following expression:

$$
P_{F}=\frac{\frac{\partial U}{\partial Q}}{\frac{\partial U}{\partial C}} \cdot\left(\frac{\partial Q}{\partial F}-\frac{\partial Q}{\partial K_{M}}\right)+w_{M}
$$

Revealing that for a family in which the mother is working, the likelihood that the family uses formal care is higher the higher is the mother's wage. Furthermore, the higher the hourly price of formal care in the market, the lower the probability of the mother taking up a paid job.

\subsection{Case b: $H_{M}=F+I \quad(\Longrightarrow \lambda>0)$}

If the number of hours of non-maternal childcare is the same as the number of hours in which the mother works, the relevant F.O.C. are the following:

$$
\begin{gathered}
\frac{\partial U}{\partial H_{M}}=0 \Longrightarrow \frac{\partial U}{\partial C} \cdot w_{M}-\frac{\partial U}{\partial L_{M}}-\lambda=0 \\
\frac{\partial U}{\partial H_{F}}=0 \Longrightarrow \frac{\partial U}{\partial C} \cdot w_{F}-\frac{\partial U}{\partial L_{F}}=0 \\
\frac{\partial U}{\partial F}=0 \Longrightarrow \frac{\partial U}{\partial L_{M}}+\left(\frac{\partial U}{\partial Q} \cdot \frac{\partial Q}{\partial F}\right)-\left(\frac{\partial U}{\partial Q} \cdot \frac{\partial Q}{\partial K_{M}}\right)-\frac{\partial U}{\partial C} \cdot P_{F}+\lambda=0
\end{gathered}
$$

By definition, $\lambda=\frac{\partial U\left(H_{M}^{*}, H_{F}^{*}, F^{*}\right)}{\partial F}$, which in this specific case is:

$$
\left[\frac{\partial U}{\partial L_{M}}+\frac{\partial U}{\partial Q} \cdot\left(\frac{\partial Q}{\partial F}-\frac{\partial Q}{\partial K_{M}}\right)-\frac{\partial U}{\partial C} \cdot P_{F}\right]
$$

The first two terms in this expression denote the marginal benefits of an extra hour of formal care, whereas the last term represents the marginal cost of this extra hour. Given that $\lambda>0$, then

$$
\frac{\partial U}{\partial L_{M}}+\frac{\partial U}{\partial Q} \cdot\left(\frac{\partial Q}{\partial F}-\frac{\partial Q}{\partial K_{M}}\right)>\frac{\partial U}{\partial C} \cdot P_{F}
$$


The marginal benefit of an extra hour of formal care are higher than the marginal cost of this extra hour. If the constraint on the number of hours of use of formal childcare did not exist, the family would use a greater quantity of it. In other words, the family does not use more formal care because it is not available in the market or they simply cannot afford it.

By comparing the mother's reservation wage with the reservation marginal cost of formal care when (i) the constraint is not binding and (ii) when it is binding, a better insight on how that restriction affects the family's decision process may be obtained. The mother's reservation wage when the constraint is binding is given by:

$$
w_{M_{0}}^{b}=\left.\frac{\frac{\partial U}{\partial L_{M}}}{\frac{\partial U}{\partial C}}\right|_{H_{M}=0 .}+\left.\frac{\lambda}{\frac{\partial U}{\partial C}}\right|_{H_{M}=0}
$$

Since $\frac{\partial U}{\partial C}>0$ and $\lambda>0$, then $w_{M_{0}}^{b}$ is unambiguously greater than $w_{M_{0}}$, and a rather intuitive result is found. Namely, when the family is constrained in the number of hours of formal care they can buy, the likelihood of the mother's participation in the labour market decreases relative to the case in which that constraint is not binding. The first F.O.C. (equation b.1) also implies that for families in which the mother is working, the presence of the constraint reduces the number of hours the mother is willing to work.

The expression for the reservation marginal cost of formal childcare when the constraint on formal childcare use is binding is:

$$
P_{F_{0}}^{b}=\left.\frac{\frac{\partial U}{\partial Q}}{\frac{\partial U}{\partial C}} \cdot\left(\frac{\partial Q}{\partial F}-\frac{\partial Q}{\partial K_{M}}\right)\right|_{F=0}+\left.\frac{\frac{\partial U}{\partial L_{M}}}{\frac{\partial U}{\partial C}}\right|_{F=0}-\frac{\lambda}{\frac{\partial U}{\partial C}}
$$

Since $\frac{\partial U}{\partial C}>0$ and $\lambda>0$, then $P_{F_{0}}>P_{F_{0}}^{b}$. When the family is constrained on

the number of hours of formal care they can use, the likelihood of their using formal care is lower than in the case in which such a constraint is not binding. For those families using formal care, F.O.C. (b.3) shows that the optimal number of hours used is lower than when there was no limit to its use.

The previous analysis provides an overview of the relationships between wages, childcare price, unearned income, the father's and the mother's work hours, and formal childcare take-up. Having described how the exogenous and the endogenous variables in this model interact to determine the optimal decision for the family's well-being, the next step is to estimate the parameters of 
the utility function. It will then be possible to derive a measure of the intensity of the relationship between the exogenous and endogenous choice variables.

Before presenting the specific econometric model, however, a further simplification is introduced. In the conceptual model, childcare quality is defined as $Q=Q\left(K_{M}, F\right)$ and so childcare quality is assumed to increase with inputs of maternal care and formal care. The contribution of each input to the overall quality is ambiguous and depends on the quality of each childcare mode relative to the others. When it comes to estimation, the relative quality of the two modes considered is assumed to be exogenously determined and no distinction is made between high and low quality care. Childcare quality enters this model by introducing proxy variables in the estimation of the price of formal childcare.

In this static modelling approach, if the family's potential to save for future consumption is ignored or, equivalently, it is assumed that the family chooses a point on the edge of their budget set, then consumption $(C)$ can be substituted by income $(Y)$. Substituting also $L_{M}$, and $L_{F}$ by their expressions in the constraints, and taking into account what has been assumed about $Q$, the model to be estimated can be expressed as:

$$
\begin{aligned}
\underset{H_{M}, H_{F}, F}{\operatorname{Max} U}= & U\left(Y, F+I-H_{M}, T-H_{F}, F ; X\right) \\
& \text { s.t. } \\
Y= & w_{M} \cdot H_{M}+w_{F} \cdot H_{F}+v-P_{F} \cdot F
\end{aligned}
$$

If it is assumed that families will use as much informal childcare as possible, then the argument $I$ will always be equal to its availability and, therefore, can be treated as an exogenous variable. Thus, the only endogenous variables in the model are $H_{M}, H_{F}$, and $F$. This implies that each family in the sample will choose the values of $H_{M}, H_{F}$, and $F$ that maximize the utility function $U=U\left(Y, L_{M}, L_{F}, F\right)$. This approach has a serious pitfall since it does not take into account the possible non-pecuniary costs of informal childcare ${ }^{3}$.

In Ribar (1995), this omission is remedied by incorporating directly into the utility function these non-pecuniary costs (or indirect costs, using Ribar's terminology). Ribar re-expresses the family's utility function as $U=U\left(Y, L_{M}, F\right)$. This utility function is assumed to increase in $Y, L_{M}$ and $F$ implying that utility decreases in informal childcare utilization and that this (dis)utility term acts as a flexible and tractable proxy for the indirect costs of informal childcare. Ribar recognizes that this approach is theoretically clumsy because while this modified utility function captures the effects of indirect costs, there is no reason to suppose that families actually have direct negative preferences regarding informal childcare. Ideally, the indirect costs of informal childcare should be

\footnotetext{
${ }^{3}$ Even if no money is paid for these services, parents may compensate the care giver for the services provided (for example, by giving a present, invitation to dinner, etc). In the cases in which such a compensation is not provided, the parents may feel indebted to the provider and these feelings of obligation could be considered as costs.
} 
incorporated into the model as shadow costs in the family's consumption. In this way an equal treatment of both formal and informal childcare would be guaranteed. The estimation of such shadow costs also falls outside the scope of our paper, and the model estimated here follows the Ribar (1995) approach, although Ribar does not include the father's labour supply among the utility's arguments.

\section{Data}

To estimate the model described above, the following data are needed: mother's weekly working hours, father's weekly working hours, mother's hourly wage, father's hourly wage, family's weekly formal childcare hours, family's weekly informal childcare hours, family's weekly non-labour income, and price of for$\mathrm{mal}^{4}$ childcare. The survey used to obtain these data for British families is the 1991/92 edition of the General Household Survey (GHS92). The GHS is an annual, multipurpose survey of people living in private households in Great Britain. The survey started in 1971/72 and, with the exceptions of the years 1997/98 and $1999 / 2000$, has been carried out continuously since then. The sample contains over 10,000 households, and interviews are conducted with household members aged over 16, generating annual information on over 18,000 individuals.

The 1991/92 edition of the GHS contains an unique section on households' childcare usage necessary to estimate the model presented above. For example, it provides information on the number of hours of formal and informal childcare used for their children under 5 and 5 to 11 . It also includes information on the different modes of formal childcare used by these families and the hourly price paid for each one of these modes (but not aggregated data on the price of childcare for under twelves). The GHS92 data were collected some twelve years ago. We are not, however, aware of a more recent data source with detailed information on childcare usage. Even though our results may not fully capture the position of British families today, the technique we propose and the analytical procedures we follow in this paper are valid if and when these data are updated.

Our sample from the GHS92 consists of all families in which the parents are married or cohabiting, not self-employed and there is at least one child aged under 5. Once excluding those families for which complete information is not available, we are left with 895 families. The summary statistics and definitions for the variables are presented in Table 1 . The definitions for most of these variables are self explanatory. The predicted natural logarithm of the mother's net hourly wage (mother's ln predicted hourly wage) has, however, been calculated using estimates obtained after maximising the Full Information Likelihood Function, which takes into account the fact that the variable hourly

${ }^{4}$ Ideally, one would have data on the hourly (non-pecuniary) cost of informal childcare. 
wage is censored. ${ }^{5}$ Table 1 also reports the descriptive statistics for the hourly wage for the subsample of mothers who work (i.e. for those mothers for whom the information on hourly wages is directly available). The predicted natural logarithm of the father's net hourly wage (father's ln predicted hourly wage) has been calculated using the same method as for the mother's predicted hourly wage. The predicted natural logarithm of the hourly childcare price per child under 5 (predicted ln hourly childcare price for $45 s$ ) per child in the age range 5-11 ( predicted ln hourly childcare price for 5 to 11s) have been estimated using the same method as that used for the estimation of the hourly wages.

\section{The econometric specification}

We model labour supply and formal childcare take-up as the outcome of a discrete choice among a finite set of alternatives, as suggested by Keane and Moffitt (1998), van Soest (1995), Duncan and Giles (1998) and Blundell et al. (1999). The econometric specification used in those papers is ideal for the estimation of the model presented above since it is more realistic to assume that individuals can not choose to work any desired amount of hours but instead choose among the limited options supplied in the market (usually not to work, to work part-time or to work full-time); it allows for non-linear and possibly nonconvex budget constraints (caused by non-linear taxes and benefit systems) ${ }^{6}$; it effectively differentiates between those individuals observed not to work ${ }^{7}$; and it has the capacity to deal with decisions at the level of the household rather than at the level of the individual. These characteristics also allow for a natural extension into simulation.

Furthermore, the discrete approach can readily incorporate fixed costs and random preference heterogeneity; it extends naturally to the introduction of

\footnotetext{
${ }^{5}$ To allow for only having wage information on working mothers, we estimated a predicted wage for all mothers by maximizing a full information likelihood function. This is a superior alternative to the more popular method of estimating predicted wages whilst taking into account the problem of selectivity bias, the Heckman two-step procedure [Pagan and Ullah (1999)]. Further discussion on this procedure and our results are included in the appendix available from the authors.

${ }^{6}$ The discrete approach allows for model tractability that is not affected by the presence of non-linear taxes and benefit systems. Non-linear taxes and benefit systems lead, in most cases, to a non-convexity of the budget set faced by the families. The way in which continuous approach estimation deals with these non-convexities complicates considerably the tractability of the models to be estimated and at the same time imposes important restrictions in the estimates obtained (for an excellent explanation of the different approaches existing to deal with non-convexities in the budget sets, see Blundell and McCurdy 1999). Moreover, the high interdependence existing between the family members' labour market decisions and the budget constraints faced by each individual may render the continuous methods computationally infeasible (Blundell et al.(1999) assert, for example, that the application of the Hausman (1985) style model to their case would be computationally infeasible).

${ }^{7}$ Specifically, it allows for differentiating, for example, between involuntarily unemployed and voluntarily unemployed.
} 
extra preference arguments (which is specially convenient in this case since we are dealing not only with labour supply arguments but also with childcare); and it allows for the estimation of the fully structural model and, therefore, consistency of the parameters with economic theory can be tested rather than imposed $^{8}$.

The formulation of the discrete approach requires that each individual (each parent, in this case) is placed into a limited set of pre-assigned working states. In the extended model dealt with here, the number of hours of formal childcare used by the family is also limited to specific values. The potential introduction of rounding errors in the hours levels considered is possibly the most important drawback to the use of the discrete approach. As a consequence of these rounding errors, the parameters estimated may depend on the hours levels chosen. The use of sensitivity analysis might help to dissipate these doubts ${ }^{9}$. We will return to discuss these issues below.

In the discrete approach, the household maximizes utility choosing $H_{M}, H_{F}$, and $F$ among limited sets of quantities. It is assumed that the mother can choose only among $P_{1}$ different number of working hours per week $\left(H_{M} \in\left\{H^{1}, H^{2}, \ldots H^{P_{1}}\right\}\right)$; that the father can choose only among $P_{2}$ different number of working hours per week $\left(H_{F} \in\left\{H^{1}, H^{2}, \ldots H^{P_{2}}\right\}\right)$; and that the family can choose only among $P_{3}$ different number of formal childcare hours per week $\left(F \in\left\{F^{1}, F^{2}, \ldots F^{P_{3}}\right\}\right)$.

The theoretical model presented above can be expressed as:

$$
\begin{gathered}
\operatorname{Max} U\left(Y, L_{M}, L_{F}, F ; X\right)=\operatorname{Max} U\left(Y\left(H_{M}, H_{F}, F\right), F+I-H_{M}, T-H_{F}, F ; X\right) \\
H_{M} \in\left\{H^{1}, \ldots, H^{P_{1}}\right\}, H_{F} \in\left\{H^{1}, \ldots, H^{P_{2}}\right\}, F \in\left\{F^{1}, \ldots, F^{P_{3}}\right\}
\end{gathered}
$$

The arguments of this utility function are the family's total income $(Y)$; the mother's hours of work $\left(H_{M}\right)$; the father's hours of work $\left(H_{F}\right)$; and the number of hours of formal childcare $(F)$. Since

$$
Y\left[H_{M}, H_{F}, F\right]=w_{M} \cdot H_{M}+w_{F} \cdot H_{F}+v-P_{F} \cdot F
$$

and $w_{M}, w_{F}$, and $v$ are exogenous variables, the family's decision variables are $H_{M}, H_{F}$ and $F$. The family chooses the combination of $H_{M}, H_{F}$ and $F$ which maximizes its utility. If each one of these specific combinations are defined as alternatives or states, then the family is observed to choose alternative $j$ if and only if:

$$
U(\text { alternative } j)>U(\text { alternative } m) \quad \nabla m \neq j
$$

\footnotetext{
${ }^{8}$ Unlike other more standard multinomial discrete choice methods (see Duncan and Giles (1996a and 1996b)).

${ }^{9}$ Van Soest (1995) and Blundell et al.(1999) present such sensitivity analysis. Van Soest's concluded that "discretising into 25 or 36 points does not make too much difference". Blundell et al. found a progressive increase in the marginal utility of income and in the marginal disutility of hours as the number of hours bands increased, however, they concluded that such differences in marginal utilities were not particularly high.
} 


\subsection{Random utilities}

Random utilities may be incorporated into the model by introducing statespecific errors in perception. For each family $i(i=1 \ldots n)$, the observed utility obtained in every state $j$ is given by:

$$
U_{i}^{*}(\text { alternative } j)=U_{i}(\text { alternative } j)+\varepsilon_{i j}
$$

If a family is observed to choose alternative $j$, then it follows that:

$$
U_{i}(\text { alternative } j)+\varepsilon_{i j}>U_{i}(\text { alternative } m)+\varepsilon_{i m} \quad \nabla m \neq j
$$

The probability of choosing state $j$ for which $H_{M}=H^{j_{1}}, H_{F}=H^{j_{2}}$, and $F=F_{j_{3}}$ is:

$$
\begin{aligned}
& \operatorname{Pr}\left[H_{M}=H^{j_{1}}, H_{F}=H^{j_{2}}, F=F_{j_{3}}\right] \\
& =\operatorname{Pr}\left[U_{i}^{*}\left(H^{j_{1}}, H^{j_{2}}, F_{j_{3}}\right)>U_{i}^{*}\left(H^{m_{1}}, H^{m_{2}}, F_{m_{3}}\right)\right] \\
& =\operatorname{Pr}\left[\begin{array}{c}
U_{i}\left(Y_{H^{j_{1}}, H^{j_{2}}, F_{j_{3}}}, F_{j_{3}}+I-H^{j_{1}}, T-H^{j_{2}}, F_{j_{3}}\right)+\varepsilon_{j}> \\
U_{i}\left(Y_{H^{m_{1}}, H^{m_{2}}, F_{m_{3}}}, F_{m_{3}}+I-H^{m_{1}}, T-H^{m_{2}}, F_{m_{3}}\right)+\varepsilon_{m}
\end{array}\right]
\end{aligned}
$$

for all combinations ${ }^{10}$ of $\left\{H^{j_{1}}, H^{j_{2}}, F_{j_{3}}\right\} \neq\left\{H^{m_{1}}, H^{m_{2}}, F_{m_{3}}\right\}$

The number of alternatives available to the family depends on the number of hours levels for $H_{M}, H_{F}$ and $F$ considered. If the number of hours levels for the mother is assumed to be $p_{1}$, the number of hours levels for the father is assumed to be $p_{2}$, and the number of hours levels for the family's weekly formal childcare take-up is assumed to be $p_{3}$, then the number of alternatives faced by the family is $\left(p_{1} \times p_{2} \times p_{3}\right)$. Thus, when making a decision, the family is assumed to take into account $j=1 \ldots . .\left(p_{1} \times p_{2} \times p_{3}\right)$ alternatives. The family makes $\left[\left(p_{1} \times p_{2} \times p_{3}\right)-1\right]$ utility-comparisons and chooses that combination of $\left(H_{M}, H_{F}, F\right)$ which maximizes its utility $U^{*}$.

The specific value of the difference $\left(U^{*}\right.$ (alternative $\left.j\right)-U^{*}$ (alternative $\left.m\right)$ ) depends on the value of the difference in the error terms in

$$
U^{*}(\text { alternative } j)=U(\text { alternative } j)+\varepsilon_{j}
$$

\footnotetext{
${ }^{10}$ There are several combinations of $H_{k}$ and $F$ for which $U\left(H^{j 1}, H^{j 2}, F_{j 3}\right)>$ $U\left(H^{m 1}, H^{m 2}, F^{m 3}\right)$ even if some of the arguments coincide in value:

1) if $F_{j 3}=F^{m 3}$,then:

a) $j 1=m 1$ and $j 2 \neq m 2$

b) $j 1 \neq m 1$ and $j 2=m 2$

c) $j 1 \neq m 1$ and $j 2 \neq m 2$

2) if $F_{j 3} \neq F^{m 3}$, then:

a) $j 1=m 1$ and $j 2=m 2$

b) $j 1 \neq m 1$ and $j 2=m 2$

c) $j 1 \neq m 1$ and $j 2 \neq m 2$

d) $j 1=m 1$ and $j 2 \neq m 2$
} 
That is, for all $m \neq j$ :

$$
\begin{aligned}
& U^{*}(\text { alternative } j)-U^{*}(\text { alternative } m) \\
& \left.=(U \text { (alternative } j)+\varepsilon_{j}\right)-\left(U(\text { alternative } m)+\varepsilon_{m}\right) \\
& =U(\text { alternative } j)-U(\text { alternative } m)+\left(\varepsilon_{j}-\varepsilon_{m}\right)
\end{aligned}
$$

Due to these error terms, the difference $U^{*}$ (alternative $j$ ) $-U^{*}$ (alternative $m$ ) is a random variable. It is because of this randomness that the likelihood of a family choosing a specific alternative can be calculated. For each family $i$ :

$$
\begin{aligned}
\operatorname{Pr}(\text { alternative } j) & =\operatorname{Pr}\left(U_{i}^{*}(\text { alternative } j)>U_{i}^{*}(\text { alternative } m)\right) \\
& =\operatorname{Pr}\left[\left(\varepsilon_{i j}-\varepsilon_{i m}\right)>\left(U_{i}(\text { alternative } m)-U_{i}(\text { alternative } j)\right)\right]
\end{aligned}
$$

In order to calculate this probability, one must specify the functional form of $U_{i}$ and make an assumption about the distribution of the error terms $\varepsilon_{i 1} \ldots \varepsilon_{i J}$ (where $J=\left(p_{1} \times p_{2} \times p_{3}\right)$ ).

Let $\eta_{i j}$ be the differences between error terms $\left(\varepsilon_{i m}-\varepsilon_{i j}\right) \quad \nabla m \neq j$; and $\Psi_{i j}$ the difference between utilities $\left(\Psi_{i j}=U_{i}(\right.$ alternative $j)-U_{i}$ (alternative $\left.m\right)$ ) $\nabla m \neq j$.

If it is assumed that $\varepsilon_{1} \ldots \varepsilon_{J}$ have identical independent extreme value distributions, the $(J-1)$ errors' differences $\eta_{i 1} \ldots \eta_{i(J-1)}$ have a joint distribution with cumulative distribution function such that:

$$
G_{\eta}\left(\Psi_{i 1} \ldots \Psi_{i(J-1)}\right)=\operatorname{Pr}\left(\eta_{i j}<\Psi_{i j}\right)=\left[1+\sum_{j=1}^{J-1} \exp \left(-\Psi_{i j}\right)\right]^{-1}
$$

Therefore, it can be shown that the selection probability has the particularly simple form:

$$
\operatorname{Pr}(\text { alternative } j / X)=\frac{\exp \left(U_{i}(\text { alternative } j)\right)}{\sum_{j=1}^{J} \exp U_{i}(\text { alternative } j)}
$$

\subsection{The finite set of alternatives}

The hours' levels considered are either 0, 20, 40 (corresponding to non-participation, part-time and full-time employment respectively) for the mother, the father or for formal childcare take-up.. Each family therefore faces 27 possible alternatives, defined by a different combination of mother's working hours, father's working hours and formal childcare take-up hours:

Alternative 1: $H_{M}=0, H_{F}=0, F=0$;

Alternative 2: $H_{M}=0, H_{F}=0, F=20$;

Alternative 3: $H_{M}=0, H_{F}=0, F=40$;

Alternative 4: $H_{M}=20, H_{F}=0, F=0$

Alternative 5: $H_{M}=20, H_{F}=0, F=20$;

Alternative $6: H_{M}=20, H_{F}=0, F=40$;

Alternative 7: $H_{M}=40, H_{F}=0, F=0$; 
Alternative 8: $H_{M}=40, H_{F}=0, F=20$;

Alternative 9: $H_{M}=40, H_{F}=0, F=40$;

Alternative 10: $H_{M}=20, H_{F}=20, F=0$;

Alternative 11: $H_{M}=20, H_{F}=20, F=20$;

Alternative 12: $H_{M}=20, H_{F}=20, F=40$;

Alternative 13: $H_{M}=40, H_{F}=40, F=0$;

Alternative 14: $H_{M}=40, H_{F}=40, F=20$;

Alternative 15: $H_{M}=40, H_{F}=40, F=40$;

Alternative 16: $H_{M}=20, H_{F}=40, F=0$;

Alternative 17: $H_{M}=20, H_{F}=40, F=20$;

Alternative 18: $H_{M}=20, H_{F}=40, F=40$;

Alternative 19: $H_{M}=40, H_{F}=20, F=0$;

Alternative 20: $H_{M}=40, H_{F}=20, F=20$;

Alternative 21: $H_{M}=40, H_{F}=20, F=40$;

Alternative 22: $H_{M}=0, H_{F}=20, F=0$;

Alternative 23: $H_{M}=0, H_{F}=20, F=20$;

Alternative 24: $H_{M}=0, H_{F}=20, F=40$;

Alternative 25: $H_{M}=0, H_{F}=40, F=0$;

Alternative 26: $H_{M}=0, H_{F}=40, F=20$;

Alternative 27: $H_{M}=0, H_{F}=40, F=40$;

Defining utility as:

$$
\max _{L_{M}, L_{F}, F} U\left(Y, L_{M}, L_{F}, F\right)
$$

and knowing that:

$$
\begin{gathered}
L_{M}=F+I-H_{M} \quad \text { if } \quad(F+I) \geq H_{M} \\
=0 \quad \text { if } \quad(F+I)>H_{M} \\
L_{F}=T-H_{F}
\end{gathered}
$$

The utility that each family $i$ enjoys in every alternative is:

$U($ alternative 1$)=U(Y,(0+I-0),(T-0), 0)$;

$U($ alternative 2$)=U(Y,(20+I-0),(T-0), 20)$;

$U($ alternative 3$)=U(Y,(40+I-0),(T-0), 40)$;

$U($ alternative 4$)=U(Y,(0+I-20),(T-0), 0)$;

$U($ alternative 5$)=U(Y,(20+I-20),(T-0), 20)$;

$U($ alternative 6$)=U(Y,(40+I-20),(T-0), 40)$;

$U($ alternative 7$)=U(Y,(0+I-40),(T-0), 0)$;

$U($ alternative 8$)=U(Y,(20+I-40),(T-0), 20)$;

$U($ alternative 9$)=U(Y,(40+I-40),(T-0), 40)$;

$U($ alternative 10$)=U(Y,(0+I-20),(T-20), 0) ;$

$U($ alternative 11$)=U(Y,(20+I-20),(T-20), 20) ;$

$U($ alternative 12$)=U(Y,(40+I-20),(T-20), 40) ;$

$U($ alternative 13$)=U(Y,(0+I-40),(T-40), 0) ;$

$U($ alternative 14$)=U(Y,(20+I-40),(T-40), 20)$; 
$U($ alternative 15$)=U(Y,(40+I-40),(T-40), 40) ;$

$U($ alternative 16$)=U(Y,(0+I-20),(T-40), 0) ;$

$U($ alternative 17$)=U(Y,(20+I-20),(T-40), 20) ;$

$U($ alternative 18$)=U(Y,(40+I-20),(T-40), 40) ;$

$U($ alternative 19$)=U(Y,(0+I-40),(T-20), 0)$;

$U($ alternative 20$)=U(Y,(20+I-40),(T-20), 20)$;

$U($ alternative 21$)=U(Y,(40+I-40),(T-20), 40)$;

$U($ alternative 22$)=U(Y,(0+I-0),(T-20), 0)$;

$U($ alternative 23$)=U(Y,(20+I-0),(T-20), 20) ;$

$U($ alternative 24$)=U(Y,(40+I-0),(T-20), 40)$;

$U($ alternative 25$)=U(Y,(0+I-0),(T-40), 0) ;$

$U($ alternative 26$)=U(Y,(20+I-0),(T-40), 20)$;

$U($ alternative 27$)=U(Y,(40+I-0),(T-40), 40)$.

As explained above, Random Disturbances are incorporated to the model in the same way as in a Multinomial Logit. That is, it is assumed they follow an iid Type I Extreme Value distribution. Therefore, for each family $(i=1 \ldots n)$, the utility in every alternative $(k=1 \ldots 27)$ is given by:

$$
\begin{aligned}
U(\text { alternative } k)= & U\left(Y, L_{M}, L_{F}, F\right)+\varepsilon_{k} \\
& \text { where } \varepsilon_{1} \ldots \varepsilon_{27} \sim \text { iid Type I Extreme Value }
\end{aligned}
$$

\subsection{The specific functional form}

In order to estimate the model just presented, a specific functional form for $U$ must be chosen. Following Ribar (1995), Keane and Moffitt (1998) and Blundell et al.(1999), the chosen functional form for the family's utility function is a generalized quadratic in its arguments, allowing for a broad array of behavioural responses $^{11}$.

The family's maximization problem is:

$$
\max U\left(C, L_{M}, L_{F}, F / \phi\right)
$$

where

$$
U=\left[\begin{array}{c}
\beta_{y} \cdot Y+\beta_{l m} \cdot L_{M}+\beta_{l f} \cdot L_{F}+\beta_{c c} \cdot F \\
+\beta_{y l m} \cdot Y \cdot L_{M}+\beta_{y l f} \cdot Y \cdot L_{F}+\beta_{y c c} \cdot Y \cdot F+ \\
\beta_{l m l f} \cdot L_{M} \cdot L_{F}+\beta_{l m c c} \cdot L_{M} \cdot F+\beta_{l f c c} \cdot L_{F} \cdot F+ \\
\theta_{y} \cdot Y^{2}+\theta_{l m} \cdot L_{M}^{2}+\theta_{l f} \cdot L_{F}^{2}+\theta_{c c} \cdot F^{2}
\end{array}\right]
$$

$>$ From the data available, the values of $Y, L_{M}, L_{F}$, and $F$ can be calculated in the following way:

$$
Y=C=\sum_{i=M, F} w_{i} \cdot H_{i}+v-P_{F} \cdot F
$$

\footnotetext{
${ }^{11}$ This functional form presents some disadvantages, however, such as not being globally concave and not guaranteed to be increasing in income across its entire range (Stern, 1997).
} 


$$
\begin{gathered}
L_{M}=F+I-H_{M} \quad \text { if } F+I \geq H_{M} \\
=0 \quad \text { if } \quad F+I<H_{M} \\
L_{F}=T-H_{F}
\end{gathered}
$$

The GHS92 provides data on $H_{M}, H_{F}, F$, and $I$ but not information on total time $(T) . T$ could be incorporated as a parameter to be estimated. However, authors like van Soest (1995) argue that the estimate of this parameter is imprecise and that giving it a set value has little impact on the other results. Following van Soest (1995), we assume that $T=80$.

The maximization problem to be estimated is the following:

$$
\max _{H_{M}, H_{F}, F} U\left(Y, H_{M}, H_{F}, F / \phi\right)
$$

where

$$
\phi=\left[\begin{array}{llllllllllllll}
\beta_{y} & \beta_{l m} & \beta_{l f} & \beta_{c c} & \beta_{y l m} & \beta_{y l f} & \beta_{y c c} & \beta_{l m l f} & \beta_{l m c c} & \beta_{l f c c} & \theta_{y} & \theta_{l m} & \theta_{l f} & \theta_{c c}
\end{array}\right]^{\prime}
$$

\subsection{Heterogeneity}

One of the advantages of the discrete approach is that it allows for the incorporation of heterogeneity so that the impact of some of the model's variables on the family's utility is allowed to depend on a set of socioeconomic variables. The effect of a particular variable on the family's utility is therefore not assumed to be the same for all families, but varies depending on the values that each family has for these socioeconomic variables.

\subsubsection{Observed heterogeneity}

Observed heterogeneity is introduced linearly through three parameters in the utility function. These parameters are $\beta_{y}, \beta_{l m}$ and $\beta_{l f}$ in expression (24). For each family in the sample:

$$
\beta_{y}=X_{y} \cdot \tau_{y}
$$

where $X_{y}$ is the set of attributes assumed to influence $\beta_{y}$; and $\tau_{y}$ is the set of parameters capturing the intensity of the relationship between each variable in $X_{y}$ and $\beta_{y}$. And similarly:

$$
\begin{gathered}
\beta_{l m}=X_{l m} \cdot \tau_{l m} \\
\beta_{l f}=X_{l f} \cdot \tau_{l f}
\end{gathered}
$$




\subsubsection{Random preference heterogeneity}

Random Preference Heterogeneity is incorporated by randomizing those same parameters:

$$
\begin{gathered}
\beta_{y}=X_{y} \cdot \tau_{y}+\zeta_{y} \\
\beta_{l m}=X_{l m} \cdot \tau_{l m}+\zeta_{l m} \\
\beta_{i l f}=X_{i l f} \cdot \tau_{l f}+\zeta_{l f}
\end{gathered}
$$

It is further assumed that these three error terms follow a trivariate normal distribution:

$$
\left(\begin{array}{c}
\zeta_{y} \\
\zeta_{l m} \\
\zeta_{l f}
\end{array}\right) \sim T V N(0, \Sigma)
$$

where $\Sigma$ is the variance and covariance matrix.

\section{The estimation}

\subsection{Without random preference heterogeneity}

When random preference heterogeneity is not introduced, the model presented above can be estimated by Maximum Likelihood. The first step before proceeding to the estimation is to build the log likelihood function to be maximized. In order to build this function, the probability that a family $i$ chooses alternative $j$ must be calculated. As discussed above, a family will choose alternative $j$ if and only if the utility obtained with this alternative is higher than the utility obtained with any of the other alternatives. Expression (23) shows how this probability is calculated. Consequently, when random preference heterogeneity is not introduced, for each family $i$ the probability of choosing the set

$$
\left[H_{M}=H^{j 1}, H_{F}=H^{j 2}, F=F_{j 3}\right]
$$

is equal to:

$$
\frac{\exp \left[U_{i}\left(Y_{H^{j 1}, H^{j 2}, F_{j 3}}, F_{j 3}+I-H^{j 1}, T-H^{j 2} / \phi\right)\right]}{\sum_{m_{1}=1}^{p_{1}} \sum_{m_{2}=1}^{p 2} \sum_{m_{3}=1}^{p 3} \exp \left[U_{i}\left(Y_{H^{j 1}, H^{j 2}, F_{j 3}}, F_{j 3}+I-H^{j 1}, T-H^{j 2} / \phi\right)\right]}
$$

where $\phi$ is the set of parameters in (25) defining the specific functional form for $U$. 
The contribution of each family to the log-likelihood function is given by:

$$
\begin{aligned}
l(\phi)= & \sum_{j_{1}=1}^{p 1} \sum_{j_{2}=1}^{p 2} \sum_{j_{3}=1}^{p 3} d_{j_{1}, j_{2}, j_{3}} \ln \operatorname{Pr}\left[H_{M}=H^{j 1}, H_{F}=H^{j 2}, F=F_{j 3}\right] \\
= & \sum_{j_{1}=1}^{p 1} \sum_{j_{2}=1}^{p 2} \sum_{j_{3}=1}^{p 3} d_{j_{1}, j_{2}, j_{3}} U\left(Y_{H^{j 1}, H^{j 2}, F_{j 3}}, F_{j 3}+I-H^{j 1}, T-H^{j 2} / \phi\right)- \\
& \sum_{m_{1}=1}^{p 1} \sum_{m_{2}=1}^{p 2} \sum_{m_{3}=1}^{p 3} U\left(Y_{H^{j 1}, H^{j 2}, F_{j 3}}, F_{j 3}+I-H^{j 1}, T-H^{j 2} / \phi\right)
\end{aligned}
$$

where

$$
\begin{aligned}
d_{j_{1}, j_{2}, j_{3}} & =1 \text { if } H_{M}=H^{j 1}, H_{F}=H^{j 2}, F=F_{j 3} \\
& =0 \text { otherwise }
\end{aligned}
$$

The log-likelihood function to maximize is, therefore:

$$
\begin{aligned}
l(\phi) & =\sum_{i=1}^{N}\left(\sum_{j_{1}=1}^{p 1} \sum_{j_{2}=1}^{p 2} \sum_{j_{3}=1}^{p 3} d_{j_{1}, j_{2}, j_{3}} \ln \operatorname{Pr}\left[H_{M}=H^{j 1}, H_{F}=H^{j 2}, F=F_{j 3}\right]\right) \\
& =\sum_{i=1}^{N}\left(\begin{array}{c}
\sum_{j_{1}=1}^{p 1} \sum_{j_{2}=1}^{p 2} \sum_{j_{3}=1}^{p 3} d_{j_{1}, j_{2}, j_{3}} U\left(Y_{H^{j 1}, H^{j 2}, F_{j 3}}, F_{j 3}+I-H^{j 1}, T-H^{j 2} / \phi\right)- \\
\sum_{m_{1}=1}^{p 1} \sum_{m_{2}=1}^{p 2} \sum_{m_{3}=1}^{p 3} U\left(Y_{H^{j 1}, H^{j 2}, F_{j 3}}, F_{j 3}+I-H^{j 1}, T-H^{j 2} / \phi\right)
\end{array}\right)
\end{aligned}
$$

\subsection{With random preference heterogeneity}

The introduction of random preference heterogeneity factors motivates the application of simulation methods in order to estimate the structural parameters. This is because the system of equations derived from the maximization of the criterion function is not analytically tractable ${ }^{12}$.

The most commonly used simulation methods are the Method of Simulated Maximum Likelihood (MSL) and the Method of Simulated Moments (MSM). The first method is simpler than the second one but it may provide inconsistent estimators if the number of draws used in the simulation is finite. The Method of Simulated Moments, instead, provides consistent estimators even for a finite number of draws. Many analysts acknowledge that the gains in simplicity when using the Method of Simulated Maximum Likelihood compensate for its main drawback, however, and advise its use over the more complex Method of Simulated Moments (Gourieroux and Monfort,1996, pages 43-44). Furthermore,

\footnotetext{
${ }^{12}$ For example, the estimation of these parameters using the method of Maximum Likelihood, requires the evaluation of integrals of order $(k+1), \mathrm{k}$ denoting the number of random heterogeneity parameters introduced. Depending on the structural model being estimated, $\mathrm{k}$ might not be very large in practice, nevertheless, numerical problems arise due to the large number of such integrals that have to be evaluated (this number is equal to the number of individuals, which may be very large in some problems (Gourieroux and Monfort,1996)).
} 
Stern (1997, page 2032) argues that recent work concludes that for problems such as ours, MSL provides more precise estimators than does MSM and that MSL is preferred in terms of statistical performance.

The Simulated Maximum Likelihood method of estimation consists in obtaining $R$ draws from the assumed distribution of the random terms (or errors) in $(26),(27),(28)$. The probability that a family $i$ chooses alternative $j$ will depend now not only on the values of the variables and parameters defining $U$, but also on the value of the simulated error terms. For each draw of errors, the probability that a family $i$ chooses alternative $j$ is calculated. Thus, $\operatorname{Pr}\left(U_{j}\right)$ is substituted by $\operatorname{Pr}\left(U_{j}, \zeta_{r}\right)$, where $\zeta_{r}$ is the set of error terms corresponding to the rth draw ${ }^{13}$. This probability can be expressed as:

$$
\operatorname{Pr}\left(U_{j}, \zeta_{r}\right)=\operatorname{Pr}\left(U_{j} / \zeta_{r}\right) \cdot f\left(\zeta_{r}\right)
$$

where $\operatorname{Pr}\left(U_{j} / \zeta_{r}\right)$ is the probability of family $i$ choosing alternative $j$, conditional on $\zeta_{r}$; and $f()$ is the density function from which the error terms have been generated.

In theoretical terms, once the utility for each one of the $R$ draws has been calculated, the probability of family $i$ choosing alternative $j$ will be:

$$
\operatorname{Pr}\left(U_{j}\right)=\int_{-\infty}^{+\infty} \operatorname{Pr}\left(U_{j}, \zeta_{r}\right) \cdot d_{\zeta_{r}}=\int_{-\infty}^{+\infty}\left(\operatorname{Pr}\left(U_{j} / \zeta_{r}\right) \cdot f\left(\zeta_{r}\right)\right) \cdot d_{\zeta_{r}}
$$

To calculate the probability of family $i$ choosing alternative $j$ once the $R$ draws of $\zeta_{r}$ have taken place, the mean of the family's probabilities of choosing alternative $j$ is required. This is:

$$
\operatorname{Pr}\left(U_{j}\right)=\frac{\sum_{r=1}^{R} \operatorname{Pr}\left(U_{j} / \zeta_{r}\right)}{R}
$$

where, $\operatorname{Pr}\left(U_{j} / \zeta_{r}\right)$ is calculated as in equation (23). Expression 34 becomes, therefore:

$$
\begin{aligned}
\operatorname{Pr}(\text { family } i \text { chooses alternative } j) & =\frac{\sum_{r=1}^{R} \operatorname{Pr}\left(U_{j} / \zeta_{r}\right)}{R} \\
& =\frac{\sum_{r=1}^{R} \frac{\exp \left(U_{i}(\text { alternative } j)\right)}{\sum_{j=1}^{J} \exp U_{i}(\text { alternative } j)}}{R}
\end{aligned}
$$

where $\mathrm{R}$ has been set to be equal to 100 (Keane and Moffitt, 1998) ${ }^{14}$.

\footnotetext{
${ }^{13} \operatorname{Pr}\left(U_{j}\right)$ should be read as the probability of family choosing alternative $j$, which depends on the family's utility in alternative $j$ (and on the family's utility in the other alternatives, but for simplicity this is not included in the expression). Similarly, $\operatorname{Pr}\left(U_{j}, \zeta_{r}\right)$ should be read as the probability of family $i$ choosing alternative $j$, which depends on the family's utility in alternative $j$ and on the values of the error terms $\zeta_{r}$.

${ }^{14}$ Keane and Moffitt (1998) report estimates computed with 500 draws and with 1000 draws,
} 


\section{$5 \quad$ Modelling participation}

When building up a model with the intention of using it for simulating policy reforms, special attention must be paid to the modelling of the participation decision (Blundell et al. 1999).

Most microsimulation studies implicitly assume the reason for observing a non-participating individual is that his/her reservation wage is higher than the wage offered in the market. Mroz (1987) provides wide empirical evidence that this characterization is not statistically suitable. Some studies have incorporated other explanations for observing an individual out of the labour market. Cogan (1980), for example, controls directly for fixed costs in estimation, and Blundell et al. (1987) differentiate between those self-reported non-participants and those unemployed but seeking work. However, as stated in Blundell et al. (1999), in these models the empirical model of participation does not explicitly depend on the detail of the tax and benefit system and the use of the estimates obtained in the microsimulation stages is not straight forward. Blundell et al.(1999) incorporate fixed costs of employment in their model by allowing for the separation of those mothers not in paid employment into "discouraged workers", "unemployed seekers" and "non-participants". The non-working males, however, are pooled together into one group and their labour market choice is treated as a simple binary decision ${ }^{15}$.

We do not introduce controls for fixed costs in this paper. We do not believe this omission will have a large impact on our estimates, however, since childcare costs (which are one of the main sources of fixed costs in the parents' labour force participation) are included among the utility function's arguments. The model estimated in our paper also differentiates those non-employed but seeking work from those who are not employed but who do not look for a job. This differentiation is made for both the father and the mother.

The GHS92 data identifies those seeking a job (involuntarily unemployed), those working, and those non-participating at all in the labour market. In order to build the likelihood function, having categorised each individual into one of these three participation groups, we need to calculate (using all the individuals in the sample) the probability of observing each one of these types.

- Probability of observing an involuntarily unemployed

The probability of being involuntarily unemployed can be calculated using a probit specification. Define, for each individual in the sample:

$$
I_{k}=1\left(I_{k}^{*}>0\right) \quad k=M, F
$$

and conclude that the point estimates of the parameters were affected relatively little, save for a slight reduction in the income elasticity. They found that the major impact of the larger number of draws was a slight increase in estimated standard errors.

${ }^{15}$ The authors justify this is due to the low variability in hours of work among working males, which hampers the identification of fixed costs and involuntary unemployment from the taste parameters which define male non-participants. 
where $I_{k}=1$ is the indicator function, which is 1 if individual $i$, who is unemployed, is looking for a job and 0 otherwise; $I_{k}^{*}=Z_{k} \cdot \delta_{k}+v_{I k}$ and $v_{I k} \sim N\left(0, \Sigma_{I}\right) ; Z_{k}$ is the set of socioeconomic variables thought to have an influence on the probability of looking for a job; and $\delta_{k}$ is the set of parameters capturing the relationship between those variables and $I_{k}^{*}$. Notice that the probability of being involuntarily unemployed is estimated separately for the mother $(k=M)$ and for the father $(k=F)$. The probability of observing an individual being involuntarily unemployed is given by:

$$
\begin{aligned}
\operatorname{Pr}(\text { being involuntarily unemployed }) & =\operatorname{Pr}\left(I_{k}^{*}>0 / z_{k}\right) \\
& =\operatorname{Pr}\left(z_{k} \cdot \delta_{k}+v_{I k}>0 / z_{k}\right) \\
& =\operatorname{Pr}\left(v_{I k}>-\left(z_{k} \cdot \delta_{k}\right) / z_{k}\right) \\
& =\Phi\left(z_{k} \cdot \delta_{k}\right)
\end{aligned}
$$

The probabilities of any of the possible combinations of working states for the mother and the father in each family in the sample can now be calculated.

- Probability of observing a non-participant mother (NPM) and a non-participant father (NPF).

$$
\begin{aligned}
\operatorname{Pr} & {\left[N P M, N P F, F=F_{j 3} / X, z_{F}, \phi\right]=} \\
& =\operatorname{Pr}\left[\begin{array}{c}
U_{i}^{*}\left(Y_{N P M, N P F, F_{j}}, F_{j 3}+I, T, F_{j_{3}} / X, \phi, \varepsilon\right)> \\
U_{i}^{*}\left(Y_{H^{m_{1}}, H^{m_{2}}, F_{m_{3}}}, F_{j 3}+I-H^{m 1}, T-H^{m 2}, F_{m_{3}} / X, \phi, \varepsilon\right)
\end{array}\right]
\end{aligned}
$$

where $U_{i}^{*}\left(Y_{N P M, N P F, F_{j_{3}}}, F_{j 3}+I, T, F_{j_{3}} / X, \phi, \varepsilon\right)$ are all those alternatives in which there is a non participant mother and a non participant father. This probability is:

$$
\operatorname{Pr}(\text { alternative } 1)+\operatorname{Pr}(\text { alternative } 2)+\operatorname{Pr}(\text { alternative } 3)
$$

or

$$
\operatorname{Pr}(\text { alternative } 1)+\ldots+\operatorname{Pr}(\text { alternative } 3)
$$

- Probability of observing a non-participant mother (NPM) and a working father.

$\operatorname{Pr}\left[N P M, H_{F}=H^{j 2}, F=F_{j 3} / X, z_{F}, \phi\right]=$ $\left(1-\Phi\left(z_{F} \cdot \delta_{F}\right)\right) \cdot \operatorname{Pr}\left[\begin{array}{c}U_{i}^{*}\left(Y_{N P M, H^{j_{2}}, F_{j_{3}}}, F_{j 3}+I, T-H^{j 2}, F_{j_{3}} / X, \phi, \varepsilon\right)> \\ U_{i}^{*}\left(Y_{H^{m_{1}}, H^{m_{2}}, F_{m_{3}}}, F_{j 3}+I-H^{m 1}, T-H^{m 2}, F_{m_{3}} / X, \phi, \varepsilon\right)\end{array}\right]$

where $U_{i}^{*}\left(Y_{N P M, H^{j_{2}}, F_{j_{3}}}, F_{j 3}+I, T-H^{j 2}, F_{j_{3}} / X, \phi, \varepsilon\right)$ are all those alternatives in which there is a non participant mother and a working father. This probability is calculated by adding up the probability of family $i$ choosing any of these alternatives, and then multiplying this by the probability of the father actually being able to find a job (i.e. $(1-\operatorname{Pr}$ (being involuntarily unemployed)) :

$$
\left(1-\Phi\left(z_{F} \cdot \delta_{F}\right)\right) \cdot[\operatorname{Pr}(\text { alternative } 22)+\ldots+\operatorname{Pr}(\text { alternative } 27)]
$$


- Probability of observing a working mother and a non-participant father (NPF).

$\operatorname{Pr}\left[H_{M}=H^{j 1}, N P F, F=F_{j 3} / X, z_{M}, \phi\right]=$ $\left(1-\Phi\left(z_{M} \cdot \delta_{M}\right)\right) \cdot \operatorname{Pr}\left[\begin{array}{c}U_{i}^{*}\left(Y_{H^{j_{1}}, N P F, F_{j_{3}}}, F_{j 3}+I-H^{j 1}, T, F_{j_{3}} / X, \phi, \varepsilon\right)> \\ U_{i}^{*}\left(Y_{H^{m_{1}}, H^{m_{2}}, F_{m_{3}}}, F_{j 3}+I-H^{m 1}, T-H^{m 2}, F_{m_{3}} / X, \phi, \varepsilon\right)\end{array}\right]$

where $U_{i}^{*}\left(Y_{H^{j_{1}}, N P F, F_{j_{3}}}, F_{j 3}+I-H^{j 1}, T, F_{j_{3}} / X, \phi, \varepsilon\right)$ are all those alternatives in which there is a working mother and a non participant father. The probability of family $i$ choosing any of these alternatives, multiplyied by the probability of the mother actually being able to find a job (i.e. $(1-\operatorname{Pr}($ being involuntarily unemployed $))$ :

$$
\left(1-\Phi\left(z_{M} \cdot \delta_{M}\right)\right) \cdot[\operatorname{Pr}(\text { alternative } 4)+\ldots+\operatorname{Pr}(\text { alternative } 9)]
$$

- Probability of observing an unemployed-seeker mother (USM) and a working father.

$\operatorname{Pr}\left[U S M, H_{F}=H^{j 2}, F=F_{j 3} / X, z_{M}, z_{F}, \phi\right]=$

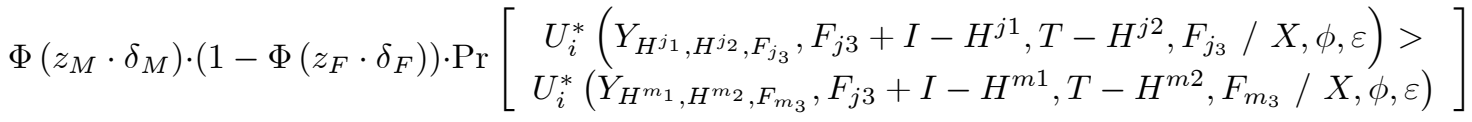

where $U_{i}^{*}\left(Y_{H^{j_{1}}, H^{j_{2}}, F_{j_{3}}}, F_{j 3}+I-H^{j 1}, T-H^{j 2}, F_{j_{3}} / X, \phi, \varepsilon\right)$ are all those alternatives in which there is a working mother and a working father. The probability of family $i$ choosing any of these alternatives, multiplied by the probability of the mother being involuntarily unemployed and by the probability of the father being able to find a job:

$$
\begin{aligned}
& \Phi\left(z_{M} \cdot \delta_{M}\right) \cdot\left(1-\Phi\left(z_{F} \cdot \delta_{F}\right)\right) \cdot \\
& {[\operatorname{Pr}(\text { alternative 10) }+\ldots+\operatorname{Pr}(\text { alternative 21)] }}
\end{aligned}
$$

- Probability of observing an unemployed-seeker mother (USM) and an unemployedseeker father (USF).

$\operatorname{Pr}\left[U S M, U S F, F=F_{j 3} / X, z_{M}, z_{F}, \phi\right]=$

$$
\begin{aligned}
& \left(\Phi\left(z_{M} \cdot \delta_{M}\right)\right) \cdot\left(\Phi\left(z_{F} \cdot \delta_{F}\right)\right) \cdot \\
& \operatorname{Pr}\left[\begin{array}{c}
U_{i}^{*}\left(Y_{H^{j_{1}}, H^{j_{2}}, F_{j_{3}}}, F_{j 3}+I-H^{j 1}, T-H^{j 2}, F_{j_{3}} / X, \phi, \varepsilon\right)> \\
U_{i}^{*}\left(Y_{H^{m_{1}}, H^{m_{2}}, F_{m_{3}}}, F_{j 3}+I-H^{m 1}, T-H^{m 2}, F_{m_{3}} / X, \phi, \varepsilon\right)
\end{array}\right]
\end{aligned}
$$

where $U_{i}^{*}\left(Y_{H^{j_{1}}, H^{j_{2}}, F_{j_{3}}}, F_{j 3}+I-H^{j 1}, T-H^{j 2}, F_{j_{3}} / X, \phi, \varepsilon\right)$ are all those alternatives in which there is a working mother and a working father. The probability of family $i$ choosing any of these alternatives, multiplied by 
the probability of the mother being involuntarily unemployed and by the probability of the father being involuntarily unemployed:

$$
\begin{aligned}
& \Phi\left(z_{M} \cdot \delta_{M}\right) \cdot \Phi\left(z_{F} \cdot \delta_{F}\right) \cdot \\
& {[\operatorname{Pr}(\text { alternative } 10)+\ldots+\operatorname{Pr}(\text { alternative 21)] }}
\end{aligned}
$$

- Probability of observing a working mother and an unemployed-seeker father (USF).

$$
\begin{aligned}
& \operatorname{Pr}[\left.H_{M}=H^{j 1}, U S F, F=F_{j 3} / X, z_{M}, z_{F}, \phi\right]= \\
&\left(1-\Phi\left(z_{M} \cdot \delta_{M}\right)\right) \cdot \Phi\left(z_{F} \cdot \delta_{F}\right) \cdot \\
& \operatorname{Pr}\left[\begin{array}{c}
U_{i}^{*}\left(Y_{H^{j_{1}}, H^{j_{2}}, F_{j_{3}}}, F_{j 3}+I-H^{j 1}, T-H^{j 2}, F_{j_{3}} / X, \phi, \varepsilon\right)> \\
U_{i}^{*}\left(Y_{H^{m_{1}}, H^{m_{2}}, F_{m_{3}}}, F_{j 3}+I-H^{m 1}, T-H^{m 2}, F_{m_{3}} / X, \phi, \varepsilon\right)
\end{array}\right]
\end{aligned}
$$

where $U_{i}^{*}\left(Y_{H^{j_{1}}, H^{j_{2}}, F_{j_{3}}}, F_{j 3}+I-H^{j 1}, T-H^{j 2}, F_{j_{3}} / X, \phi, \varepsilon\right)$ are all those alternatives in which there is a working mother and a working father. The probability of family $i$ choosing any of these alternatives, multiplied by the probability of the mother being able to find a job and by the probability of the father being involuntarily unemployed:

$$
\begin{aligned}
& \left(1-\Phi\left(z_{M} \cdot \delta_{M}\right)\right) \cdot \Phi\left(z_{F} \cdot \delta_{F}\right) \cdot \\
& {[\operatorname{Pr}(\text { alternative } 10)+\ldots+\operatorname{Pr}(\text { alternative } 21)]}
\end{aligned}
$$

- Probability of observing a working mother and a working father.

$$
\begin{aligned}
\operatorname{Pr} & {\left[H_{M}=H^{j 1}, U S F, F=F_{j 3} / X, z_{M}, z_{F}, \phi\right]=} \\
& \left(1-\Phi\left(z_{M} \cdot \delta_{M}\right)\right) \cdot\left(1-\Phi\left(z_{F} \cdot \delta_{F}\right)\right) \cdot \\
& \cdot \operatorname{Pr}\left[\begin{array}{c}
U_{i}^{*}\left(Y_{H^{j_{1}}, H^{j_{2}}, F_{j_{3}}}, F_{j 3}+I-H^{j 1}, T-H^{j 2}, F_{j_{3}} / X, \phi, \varepsilon\right)> \\
U_{i}^{*}\left(Y_{H^{m_{1}}, H^{m_{2}}, F_{m_{3}}}, F_{j 3}+I-H^{m 1}, T-H^{m 2}, F_{m_{3}} / X, \phi, \varepsilon\right)
\end{array}\right]
\end{aligned}
$$

where $U_{i}^{*}\left(Y_{H^{j_{1}}, H^{j_{2}}, F_{j_{3}}}, F_{j 3}+I-H^{j 1}, T-H^{j 2}, F_{j_{3}} / X, \phi, \varepsilon\right)$ stands for all those alternatives in which there is a working mother and a working father. The probability of family $i$ choosing any of these alternatives, multiplied by the probability of the mother being able to find a job and by the probability of the father being able to find a job:

$$
\begin{aligned}
\left(1-\Phi\left(z_{M} \cdot \delta_{M}\right)\right) \quad & \cdot\left(1-\Phi\left(z_{F} \cdot \delta_{F}\right)\right) \cdot \\
& {[\operatorname{Pr}(\text { alternative } 10)+\ldots+\operatorname{Pr}(\text { alternative } 21)] }
\end{aligned}
$$

\section{The results}

As discussed above, we use data from the 1991/92 edition of the GHS which contains a unique section on households' childcare information. Our sample 
consists of all families in which the parents are married or cohabiting, not selfemployed and in which there is at least one child aged under 5. Once removing those families for which complete information is not available, we are left with 895 families.

Table 2 reports the structural parameter estimates, together with estimated standard errors for the model with time constraints, and also relaxing these time constraints (discussed further below). The parameter estimates are obtained after dividing the utility function's arguments ${ }^{16}$ by 100 . Furthermore, due to the introduction of preference heterogeneity, the parameters $\beta_{y}, \beta_{l m}$, and $\beta_{l f}$ are not obtained directly from the estimation program. Instead, $\beta_{y}$, $\beta_{l m}, \beta_{l f}$ are obtained by substituting, in equations (26), (27) and (28), the parameters $\tau_{y}, \tau_{l m}, \tau_{l f}$ by their estimates ${ }^{17}$. The values for $\beta_{y}, \beta_{l m}, \beta_{l f}$ have been calculated by averaging these estimated parameters for each family in the sample.

Table 3 presents the model's estimated marginal utilities for each family in the sample:

$$
\frac{\partial U}{\partial H_{M}} ; \quad \frac{\partial U}{\partial H_{F}} ; \quad \frac{\partial U}{\partial F} ; \quad \frac{\partial U}{\partial v}
$$

where the expression for $U$ corresponds to equation (24), and where $v$ is the family's unearned income. The values in Table 3 represent the sample's average of these individual (i.e. per family) marginal utilities. These marginal utilities provide information on the decision process leading these families to those reactions: knowing the impact of different resource levels on the family's utility, it is possible to see how families make decisions on the allocation of these resources.

Table 4 reports the estimated uncompensated elasticities calculated as the average over the whole sample's individual elasticities ${ }^{18}$, and for various subsamples which will be discussed further in subsection 6.1 below. For each family in the sample, the following uncompensated elasticities have been calculated:

\footnotetext{
16 This "adjustment" has been made due to limitations in computing power.

${ }^{17}$ Results for the vectors $\tau_{y}, \tau_{l m}, \tau_{l f}$. are available from the authors on request.

${ }^{18}$ It is, of course, not possible to compute an individual's labour supply elasticity unless this individual is working. Similarly, it is not possible to compute a family's formal childcare demand elasticity unless this family is using formal childcare. When calculating the average mother's labour supply elasticities shown in Table 4, the families with non-working mothers have been excluded from the sample. To calculate the father's labour supply elasticities, the families with non-working fathers have been excluded from the sample. Finally, those families not using formal childcare have also been excluded from the sample in order to calculate the formal childcare demand elasticities.
} 


$$
\begin{aligned}
& \frac{\partial H_{M}^{*}}{\partial w_{M}} \cdot \frac{w_{M}}{H_{M}} ; \frac{\partial H_{M}^{*}}{\partial w_{F}} \cdot \frac{w_{F}}{H_{M}} ; \frac{\partial H_{M}^{*}}{\partial P_{F}} \cdot \frac{P_{F}}{H_{M}} ; \frac{\partial H_{M}^{*}}{\partial v} \cdot \frac{v}{H_{M}} \\
& \frac{\partial H_{F}^{*}}{\partial w_{F}} \cdot \frac{w_{F}}{H_{F}} ; \quad \frac{\partial H_{F}^{*}}{\partial w_{M}} \cdot \frac{w_{M}}{H_{F}} ; \frac{\partial H_{F}^{*}}{\partial P_{F}} \cdot \frac{P_{F}}{H_{F}} ; \frac{\partial H_{F}^{*}}{\partial v} \cdot \frac{v}{H_{F}} \\
& \frac{\partial F^{*}}{\partial P_{F}} \cdot \frac{P_{F}}{F} ; \quad \frac{\partial F^{*}}{\partial w_{M}} \cdot \frac{w_{M}}{F} ; \frac{\partial F^{*}}{\partial w_{F}} \cdot \frac{w_{F}}{F} ; \frac{\partial F^{*}}{\partial v} \cdot \frac{v}{F}
\end{aligned}
$$

where

$$
\begin{aligned}
& H_{M}^{*}\left(w_{M}, w_{F}, P_{F}, v\right) \\
& H_{F}^{*}\left(w_{M}, w_{F}, P_{F}, v\right) \\
& F^{*}\left(w_{M}, w_{F}, P_{F}, v\right)
\end{aligned}
$$

have been obtained after solving the 3 -equation system resulting from the maximisation of the programme in expression (24):

$$
\frac{\partial U}{\partial H_{M}}=\mathbf{0} ; \quad \frac{\partial U}{\partial H_{F}}=\mathbf{0} ; \quad \frac{\partial U}{\partial F}=\mathbf{0}
$$

The elasticities quantify the reactions (changes in \%) of two-parent British families with children aged under 5 to a $1 \%$ increase in the value of the relevant explanatory variable. Combining information provided in Tables 2, 3 and 4 leads to the following findings:

- The marginal utility from the mother's working hours is negative for families with working mothers (-6.81 in column 3 of Table 2 ) and positive for families with non-working mothers ( 0.48 in column 2 of Table 3$)$. Implying that, on average, a family with a non-working mother will increase utility if the mother enters the labour market, whereas a family with a working mother will increase utility if the mother decreases the number of working hours.

- British mothers' labour supply elasticity to their own wage is negative (0.51 in Column 1 of Table 4). An increase in the mothers' hourly wages is assocated with, on average, a decrease in British mothers' working hours. This result is not surprising given that the marginal utility of the mother's work is negative.

- The estimated elasticities also reveal, however, that the negative effect of an increase in hourly wages on the mother's working hours is higher for families with mothers working part-time (-0.51 compared to -0.26 in column 3 of Table 4 , row 1$)^{19}$, in spite of these women's relatively lower

\footnotetext{
${ }^{19}$ The elasticity for the whole sample of families with working mothers is much higher than the elasticity for the subsample of families with mothers working full-time. Thus, the elasticity for part-time working mothers is higher than for full-time working mothers.
} 
marginal disutility of work. A possible explanation for this apparently contradictory result might be that part-time workers enjoy greater flexibility over the choice of working hours or that they work part-time due to childcare limitations (price and/or availability).

- The estimated marginal utility of formal childcare use is positive for families with working mothers ( 0.22 in column 1 of Table 4$)$ implying that these families would prefer to increase the number of hours of formal childcare they use at present. That they do not do so hints to the possible existence of an availability constraint for this type of childcare. The combination of this result with the already mentioned working women's negative marginal utility of work, suggests the motivation for wanting to increase the number of hours of formal childcare is not to increase the number of working hours per se, but to reduce the number of hours of informal childcare use.

- This is corroborated by the estimated negative elasticities of formal childcare demand to the mother's wage ( -0.75 in column 1 of Table 4$)$, to the father's wage (-4.42) and to the family's non-labour income (-0.06), which indicate that families with working women reduce the demand for formal childcare when these economic variables increase.

- The negative elasticities of the mother's labour supply to her own wage(0.51 in Column 1 of Table 4), to her partner's wage (-2.93), and to the family's non-labour income $(-0.20)$ suggest that in order to reduce the formal childcare demand families decrease the mother's working hours. The finding that the negative elasticities of formal childcare demand are higher for families with part-time working mothers provides a supplementary explanation to these women's higher wage labour supply elasticity (as mentioned above).

- The negative elasticities of formal childcare demand, and the negative elasticities of the mother's labour supply, could also arise if families believe an increase in maternal childcare time raises the overall quality of childcare relatively more than an increase in formal childcare time, rather than simply a desire to reduce the use of informal childcare.

- The positive elasticity of formal childcare demand to its hourly price suggests that British families respond to a rise in the price of formal childcare by increasing demand for it. This implies that they may perceive the price of formal childcare as an indicator of its quality.

- The positive elasticity of the mother's labour supply to the hourly price of formal child accords with British mothers being prepared to increase their working hours if they could rely on high-quality paid childcare. The relatively large value of this elasticity compared to the family's formal childcare demand elasticities suggests that childcare quality is a major concern when families decide on the mother's working hours. The family's 
decisions on the mother's working hours may be strongly conditioned by the (lack of) availability of high-quality formal childcare.

- The marginal utility of formal childcare is negative for families with nonworking mothers and for families with non-working fathers. This result might seem counterintuitive as these families are not facing a physical constraint to reducing the number of hours of formal childcare, however, these families may perceive the use of a few hours of formal childcare as a means to increase overall childcare quality.

- When turning to the fathers' labour supply, the most surprising result is that the estimated average marginal utility of the fathers' working hours is positive. The estimated father's labour supply elasticity to his own wage is positive and relatively high (0.93 in column 2 of Table 4). This could imply that when British fathers react to an increase in wages, the income effect is higher than the substitution effect.

- The estimated average father's labour supply elasticity to the family's non-labour income is almost zero $\left(-1.8 \times 10^{-6}\right.$ in column 2 of Table 4$)$. This suggests that, after all, the "direct" income effect might not be playing such an important role on the fathers' reaction to an increase in hourly wages. This result might also appear not to be in line with neoclassical theory. Both the positive marginal utility of the father's working hours and his positive wage labour supply elasticity do not appear as counterintuitive given that we are looking at the labour supply decision of a whole family, and not at one isolated individual in this family. In addition, the family under study is of a rather particular type (i.e., a family with pre-school age children).

To reiterate, our estimates suggest the labour supply decision of each family member is not taken separately but are made considering the family as a whole. These results also suggest that the opportunity cost of the father's working time is very close to zero, whereas the mother's working time opportunity cost is rather high because she is a valuable source of childcare. These highly divergent opportunity costs, together with the family's childcare related need for extra income, are no doubt crucial for the family's positive marginal utility of the father's work as well as for the positive father's wage labour supply elasticity. These arguments might also explain why the estimated elasticity of the father's labour supply to the mother's hourly wage is positive ${ }^{20}$.

\footnotetext{
${ }^{20}$ As seen earlier, the family's reaction to an increase in the mother's hourly wage is the reduction in her working hours. This reduction in the mother's working hours would be (partially) compensated by an increase in the father's working hours.
} 


\subsection{Robustness analysis}

Before proceeding to summarize the main conclusions drawn from the estimation of the model, we now discuss results with different subsamples and for the model without time constraints. The purpose of this additional estimation is to consider the robustness of the results and to directly consider how important the assumption that the mother is the only provider of parental childcare has been on the estimates presented.

The elasticity results presented in Table 4 are calculated over the full sample (families with at least one child aged under 5); for the subsample of families with at least one child aged under three years; for those families using formal childcare; and for those families with at least one child aged under three and using formal childcare. The elasticities estimated for the subsample of families with children aged under three are, in general, smaller than the elasticities estimated for the whole sample. This suggests that families with younger children are facing more constraints when allocating the mother's time between working and childcare. These constraints may be motivated by a greater reticence to use formal care for children aged under three, compared to its use for older children.

So far we have considered the following model with time constraints:

$$
\begin{aligned}
\underset{H_{M}, H_{F}, F}{\operatorname{Max} U}= & U\left(Y, F+I-H_{M}, T-H_{F}, F ; X\right) \\
& \text { s.t. } \\
Y= & w_{M} \cdot H_{M}+w_{F} \cdot H_{F}+v-P_{F} \cdot F
\end{aligned}
$$

Relaxing the mother's time constraint, the father's time constraint, the child's time constraint, and the minimum childcare requirement results in the nonconstrained model:

$$
\begin{aligned}
\underset{H_{M}, H_{F}, F}{\operatorname{MaxU}}= & U\left(Y, H_{M}, H_{F}, F ; X\right) \\
& \text { s.t. } \\
Y= & w_{M} \cdot H_{M}+w_{F} \cdot H_{F}+v-P_{F} \cdot F \\
F+I< & H_{M}
\end{aligned}
$$

Results for the estimation of this model are provided in columns 3 and 4 of table 2, the lower panel of table 3 , and table 5 . These results reveal that the estimates of the marginal utility of the father's working hours and of the father's wage labour supply elasticity continue being positive, and that the estimate of the marginal utility of the mother's working hours and of the mother's wage's labour supply elasticity continue being negative. Thus, even when not imposing the restriction that only the mother's time is to be allocated to childcare, the estimates obtained continue to reveal that for the average British family, the opportunity cost of the mother's working time is much higher than the father's. It would appear that the almost exclusive involvement of 
mothers in childcare concluded from the estimates of the model with constraints, can also be concluded from the estimates of the non-constrained model.

The non-constrained model, however, does not consistently explain the dynamics followed by the family when deciding on their demand for formal childcare. On one hand it estimates a negative marginal utility of formal childcare and, on the other hand, it estimates an increase in formal childcare demand as a response to an increase in the mother's wage, the father's wage, and the family's non-labour income, together with a negative elasticity of the mother's labour supply both to her own wage and to the family's non-labour income. The finding of such inconsistencies suggests that the restricted model provides a better picture of the reality of the decision process followed by families with pre-school children.

\section{Conclusions}

In the typical British family with at least one child aged under 5, the mother is the preferred provider of parental childcare. Our results show the mother's labour supply decision is influenced by childcare-related considerations to a greater extent than is the father's. Our estimates also show that when British families can afford to reduce the number of hours of informal childcare, they prefer to do so by increasing the number of hours of maternal care rather than increasing their use of formal childcare of a given quality. Thus, it appears that British working mothers are willing to reduce their working hours in order to increase the time they spend looking after their children.

Families appear to use the price of formal childcare as an indicator of its quality. The higher the price of formal childcare, the higher its demand and the higher the number of hours British mothers are willing to work. If more high-quality childcare was available, British mothers may be willing to reduce the number of hours of maternal childcare and to increase their working hours. There is a minimum amount of formal childcare that is considered to be nonsubstitutable but that, once having this, families use as little as possible extra formal childcare. This result suggests that (at least at the time of the survey) British families may not have had access to formal childcare of high-enough quality.

Our estimates for families with non-working mothers indicate that they wish to use formal childcare for a small number of hours but having reached this minimum level they do not increase its use any further. British non-working mothers have a low incentive to look for a job since the family's increase in utility when the mother takes up a paid job is considerably smaller than the family's decrease in utility when using extra hours of formal childcare ${ }^{21}$.

${ }^{21}$ It could be that if these families had access to higher quality formal child care they would 
To reiterate, we find that working mothers do not increase their working hours as a reaction to an increase in hourly wages, rather, British mothers may react to an increase in hourly wages by reducing their working hours.

A major way of inducing British working mothers to increase their working hours is by providing higher quality formal childcare. Thus, policy aiming at increasing British mothers of pre-school children's working hours may need to address improving the quality of formal childcare. Our estimates do not allow us to conclude on whether or not non-working mothers' dislike for formal childcare would decrease if they had access to high-quality formal childcare. If we assume so, and since these women's estimated marginal utility of work is positive, we might expect that if formal childcare of higher quality was made available to them, the number of non-working British mothers willing to join the labour force would increase.

\section{References}

Blank, R.M. (2001). Declining caseloads/increased work: What can we conclude about the effects of welfare reform. Economic Policy Review, 7(2), 25-36.

Blundell, R., Chiappori, P.A., Magnac,T.and Walker, I. (1997). Collective labour supply: Heterogeneity and nonparticipation. Institute for Fiscal Studies Working Paper.

Blundell, R., Duncan, A., MacCrae, J. and Meghir, C. (1999). Household labour supply, childcare costs and tax credits. Institute for Fiscal Studies Conference Papers 1999.

Blundell, R., Duncan, A., McCrae, J. and Meghir, C. (2000). The labour market impact of the working families tax credit. Fiscal Studies, 21(1), 75-103.

Blundell, R. and Hoynes, H. (2004). Has 'in-work' benefit reform helped the labour market. in Card, D. Blundell, R and Freeman, R (editors). Seeking a Premier Economy. (NBER, Chicago).

Blundell, R. and Macurdy, T. (1999). Labour supply: A review of alternative approaches. In O. Ashenfelter and D. Card (Eds.), Handbook of Labour Economics, volume 3a. Amsterdam: Elsevier Science BV.

Budd, J.W. and Mumford, K. (2004). Trade unions and family-friendly policies in Britain. Industrial and Labor Relations Review 57(2), 204-222.

Caracciolo, E. (2001). The family-friendly workplace: The EC position. International Journal of Comparative Labour Law and Industrial Relations, 17(3), 323-344.

Chevalier, A., and Viitanen, T. (2002). The supply of childcare in Britain: Do mothers queue for childcare? Mimeo, University College Dublin.

Chiappori, P. (1997). Introducing household production in collective models of labour supply. Journal of Political Economy, 105, 191-209.

increase the number of hours of formal child care use and, thus, the likelihood that the mother wishes to take up a paid job. Unfortunately, the model estimated can not explain whether this is really happening. 
Chiuri, M. (1998). The unitary vs collective model of household labour supply with childcare: An empirical test on a sample of Italian households. University of York Working Papers.

Cogan, J. (1980). Labour supply with costs of labor market entry. In J. Smith (Ed.), Female labor supply: theory and estimation. Princeton, NJ: Princeton University Press.

Duncan, A. and Giles, C. (1994). A simultaneous probability model of childcare take-up and labour force participation. Mimeo, University of York.

Duncan, A. and Giles, C. (1996a). Labour supply incentives and recent family credit reforms. Economic Journal, 106, 142-155.

Duncan, A. and Giles, C. (1996b). Should we subsidise pre-school childcare, And if so, how? Fiscal Studies, 17(3), 39-61.

Duncan, A. and Giles, C. (1998). The labour market impact of the working families tax credit in the UK. Mimeo, University of York.

Duncan, A., Paull, G and Taylor, J. (2001). Price and quality in the UK childcare market. Institute for Fiscal Studies Working Paper WP01/14.

Ellwood, E. 2000. Anti-poverty policy for families in the next century: From welfare to work - and worries. Journal of Economic Perspectives, 14(1), 187-198.

Gershuny, J. (2003). Web use and net nerds: A Neo Functionalist analysis of the impact of information technology in the home. Social Forces 82(1), 139-166.

Gourieroux, C and Monfort, A. (1996). Simulation-based econometric methods. Oxford, UK: Oxford University Press.

Keane, M. and Moffitt, R. (1998). A structural model of multiple welfare program participation and labor supply. The International Economic Review, $39(3), 553-589$.

Killingsworth, M. (1983). Labour supply. Cambridge UK: Cambridge University Press.

Meyer, B.D., and Rosenbaum, D. T. 2001. Welfare, the earned income tax credit and the labor supply of single mothers. Quarterly Journal of Economics, 66 (3), 1063-1114.

Metcalf, H. (1990) Retaining women employees: measures To counteract labour shortage. IMS Report 190. Brighton: Institute of Manpower Studies

Michalopoulos, C., Robins P. and Garfinkel, I. (1992). A structural model of labor supply and childcare demand. Journal of Human Resources, 27(1), $166-203$.

Mroz, T. (1987). The sensitivity of an empirical model of married women's hours of work to economic and statistical assumptions. Econometrica, 55(4), $755-799$.

OJL (2003) 197/13, 5.8.2003.

Pagan, A. and Ullah, U. (1999). Nonparametric econometrics. Cambridge UK: Cambridge University Press.

Ribar, D. (1995). A structural model of childcare and the labour supply of married women. Journal of Labor Economics, 13, 558-597.

HM Treasury (2004). Choice for parents, the best start for children: a ten year strategy for childcare. December. Norwich, UK: Her Majesty's Stationery Office. 
Stern, S. (1997). Simulation-based estimation. Journal of Economic Literature, 35, 2006-2039.

Van Soest, A. (1995). Structural models of family labor supply: A discrete choice approach. The Journal of Human Resources, 30(1), 63-88.

Van Soest, A. and Kapteyn, A. (1993). Coherency and regularity of demand systems with equality and inequality constraints. Journal of Econometrics,57, $161-188$. 
Table 1: Descriptive statistics for British families with at least one child aged under five.

\begin{tabular}{|c|c|c|c|c|}
\hline Variable name & Obs & Mean & Std Dev & Variable definition \\
\hline mother working & 895 & 0.439 & 0.49 & mother participates in the labour market \\
\hline mother desire & 895 & 0.481 & 0.49 & mother desires to participate in the labour market \\
\hline age & 895 & 30.119 & 5.27 & mother's age \\
\hline mother university & 895 & 0.078 & 0.27 & mother has a university degree or higher \\
\hline father university & 895 & 0.138 & 0.34 & father has a university degree or higher \\
\hline college & 895 & 0.194 & 0.39 & A-levels (end of secondary school) $<$ mother's education $<$ university degree \\
\hline father's work pattern & 895 & 1.662 & 0.74 & father does not work $=0$, part-time $=1$, full-time $=2$ \\
\hline presence children aged $<3$ & 895 & 0.699 & 0.46 & presence of child/ren in the household aged less than 3 years \\
\hline presence children 12 to 18 & 895 & 0.081 & 0.27 & presence of child/ren in the household aged 12 to 18 years \\
\hline number children aged $<5$ & 895 & 1.318 & 0.52 & number of child/ren in the household aged less than 12 years \\
\hline grandparent present & 895 & 0.021 & 0.14 & grandparent living in the house \\
\hline use informal childcare & 895 & 0.345 & 0.47 & use free childcare only \\
\hline use formal childcare & 895 & 0.393 & 0.49 & use paid childcare \\
\hline pred ln mother's hourly wage & 895 & 1.281 & 0.24 & predicted ln mother's net hourly wage \\
\hline ln mother’s hourly wage & 393 & 1.350 & 0.65 & ln mother's net hourly wage (working mothers) \\
\hline pred ln father's hourly wage & 895 & 1.700 & 0.25 & predicted ln father's net hourly wage \\
\hline ln father's net wage & 749 & 1.709 & 0.51 & ln father's net hourly wage (working fathers) \\
\hline pred hourly cc price per u5 & 895 & 1.600 & 0.60 & predicted childcare price per child aged under 5 \\
\hline hourly cc price per u5 & 573 & 0.546 & 0.82 & childcare price per child aged under 5 \\
\hline In family’s unearned income & 895 & 5.404 & 0.59 & ln unearned weekly income (with father's wage) \\
\hline ln family’s unearned income & 895 & 3.277 & 0.93 & ln unearned weekly income (without father's wage) \\
\hline
\end{tabular}

Source: General Household Survey 1991/92 Edition. 
Table 2: Parameter estimates. Model with and without time constrants.

\begin{tabular}{|c|c|c|c|c|c|}
\hline & \multicolumn{2}{|c|}{ With time constraints } & & \multicolumn{2}{|c|}{ Without time constraints } \\
\hline & Parameters & t-value & & Parameters & t-value \\
\hline$\theta_{y}$ & 0.0190 & 0.078 & $\theta_{y}$ & -0.1836 & -0.587 \\
\hline$\theta_{l m}$ & -29.0130 & $-3.648 * * *$ & $\theta_{h m}$ & -41.6488 & $-2.577 * * *$ \\
\hline$\theta_{\text {lf }}$ & 67.3319 & $4.598 * * *$ & $\theta_{h f}$ & 10.8895 & 0.374 \\
\hline$\theta_{C C}$ & 5.4284 & $1.642 * *$ & $\theta_{C C}$ & -9.9644 & $-3.449 * * *$ \\
\hline$\beta_{c c}$ & 3.4198 & 0.437 & $\beta_{c c}$ & -4.8621 & $-1.302 *$ \\
\hline$\beta_{y l m}$ & 4.4596 & $2.385^{* * *}$ & $\beta_{y h m}$ & -1.9211 & -0.610 \\
\hline$\beta_{y l f}$ & 7.5769 & 1.553 & $\beta_{y h f}$ & -7.2049 & $-1.358^{*}$ \\
\hline$\beta_{y c c}$ & -1.3472 & -1.141 & $\beta_{y c c}$ & 0.3869 & 0.446 \\
\hline$\beta_{\text {lmlf }}$ & 35.8340 & $1.805^{* *}$ & $\beta_{h m h f}$ & 160.0120 & $3.435^{* * *}$ \\
\hline$\beta_{\text {Imcc }}$ & -15.1186 & $-2.389 * * *$ & $\beta_{\text {hmcc }}$ & 3.9053 & 0.779 \\
\hline$\beta_{l f c c}$ & -32.2893 & $-2.188 * *$ & $\beta_{h f c c}$ & 6.2424 & 0.708 \\
\hline$\beta_{y}$ & -0.4444 & n.a. & $\beta_{y}$ & 4.9865 & n.a. \\
\hline$\beta_{l m}$ & -13.6521 & n.a. & $\beta_{h m}$ & -52.6139 & n.a. \\
\hline$\beta_{\text {lf }}$ & -91.2811 & n.a. & $\beta_{h f}$ & 23.9383 & n.a. \\
\hline$\zeta_{y l m}$ & -10.2650 & $-3.289 * * *$ & $\zeta_{y h m}$ & -26.8778 & $-3.550 * * *$ \\
\hline$\zeta_{y l f}$ & 1.9538 & 0.575 & $\zeta_{y h f}$ & 22.6040 & $2.717 * * *$ \\
\hline$\zeta_{\text {Imlf }}$ & 7.0305 & $1.308^{*}$ & $\zeta_{h m h f}$ & 3.9454 & 0.918 \\
\hline Number & ervations & 895 & & & 895 \\
\hline Mean L & lihood & -2.4160 & & & -2.5076 \\
\hline
\end{tabular}

Source: General Household Survey 1991/92 Edition 
Table 3: Marginal utility estimates. Families with child/ren aged under five. Model with and without time constraints.

\begin{tabular}{|c|c|c|c|c|c|c|c|c|c|c|}
\hline & $\begin{array}{l}\text { whole } \\
\text { sample }\end{array}$ & $\begin{array}{c}\text { non } \\
\text { working } \\
\text { mothers }\end{array}$ & $\begin{array}{l}\text { working } \\
\text { mothers }\end{array}$ & $\begin{array}{l}\text { fulltime } \\
\text { working } \\
\text { mothers }\end{array}$ & $\begin{array}{c}\text { non } \\
\text { working } \\
\text { fathers }\end{array}$ & $\begin{array}{l}\text { working } \\
\text { fathers }\end{array}$ & $\begin{array}{c}\text { fulltime } \\
\text { working } \\
\text { fathers }\end{array}$ & $\begin{array}{c}\text { both } \\
\text { parents } \\
\text { working }\end{array}$ & $\begin{array}{c}\text { both } \\
\text { parents } \\
\text { working } \\
\text { fulltime }\end{array}$ & $\begin{array}{l}\text { not using } \\
\text { formal } \\
\text { childcare }\end{array}$ \\
\hline $\begin{array}{l}\text { Model with time } \\
\text { constraints }\end{array}$ & (1) & (2) & (3) & (4) & (5) & (6) & (7) & (8) & (9) & (10) \\
\hline Mothers working hours & -2.72 & 0.48 & -6.81 & -9.44 & -2.06 & -2.85 & -2.79 & -6.43 & -8.29 & -3.30 \\
\hline Fathers working hours & 28.76 & 26.18 & 32.05 & 29.56 & 1.06 & 34.17 & 34.54 & 33.86 & 32.53 & 25.86 \\
\hline Family income & 2.87 & 3.13 & 2.53 & 2.45 & 4.93 & 2.46 & 2.50 & 2.39 & 2.25 & 2.91 \\
\hline Hours of formal childcare & -4.76 & -9.49 & 1.27 & 4.29 & -12.17 & -3.31 & -3.34 & 1.25 & 3.67 & -5.12 \\
\hline \multicolumn{11}{|l|}{$\begin{array}{l}\text { Model without time } \\
\text { constraints }\end{array}$} \\
\hline Mothers working hours & -8.71 & -9.25 & -8.09 & -17.95 & -65.71 & - & 2.44 & -3.34 & -10.36 & -12.38 \\
\hline Fathers working hours & 27.66 & 13.45 & 45.80 & 60.50 & 16.13 & - & 29.92 & 45.07 & 59.46 & 20.75 \\
\hline Family income & 1.20 & 2.03 & 0.15 & -0.02 & 5.00 & - & 0.46 & -0.08 & -0.41 & 1.89 \\
\hline Hours of formal childcare & -2.25 & -2.40 & -2.07 & -2.52 & -4.61 & - & -1.79 & -1.93 & -2.36 & -1.47 \\
\hline
\end{tabular}

Source: General Household Survey 1991/92 Edition 


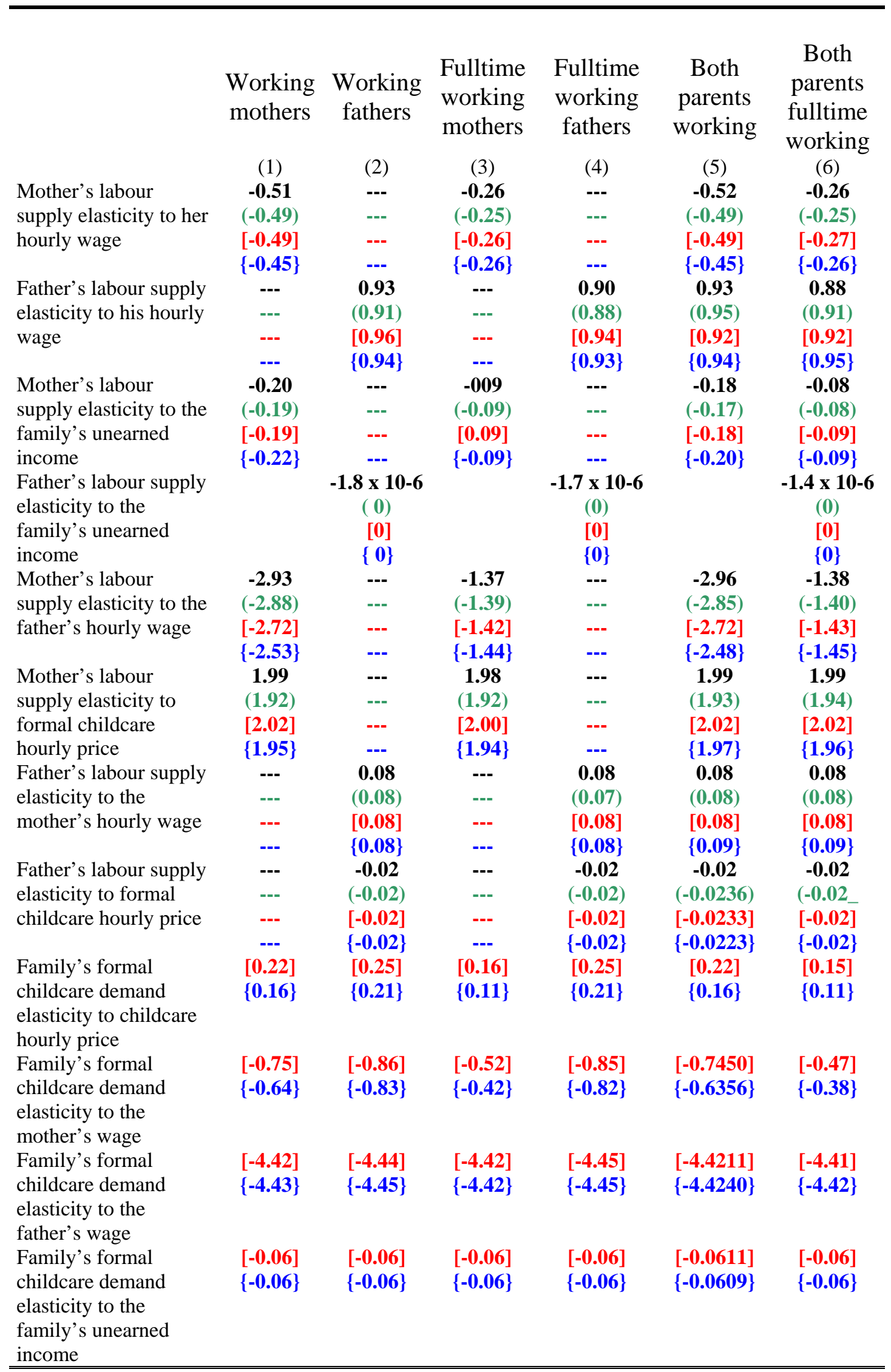

Source: General Household Survey 1991/92 Edition. No parentheses is whole sample; sub-sample of families with ( ) children aged under three; [ ] families using formal childcare; \{\} with children aged under three and using formal childcare 
Table 5. Elasticities estimates. Model without time constraints.

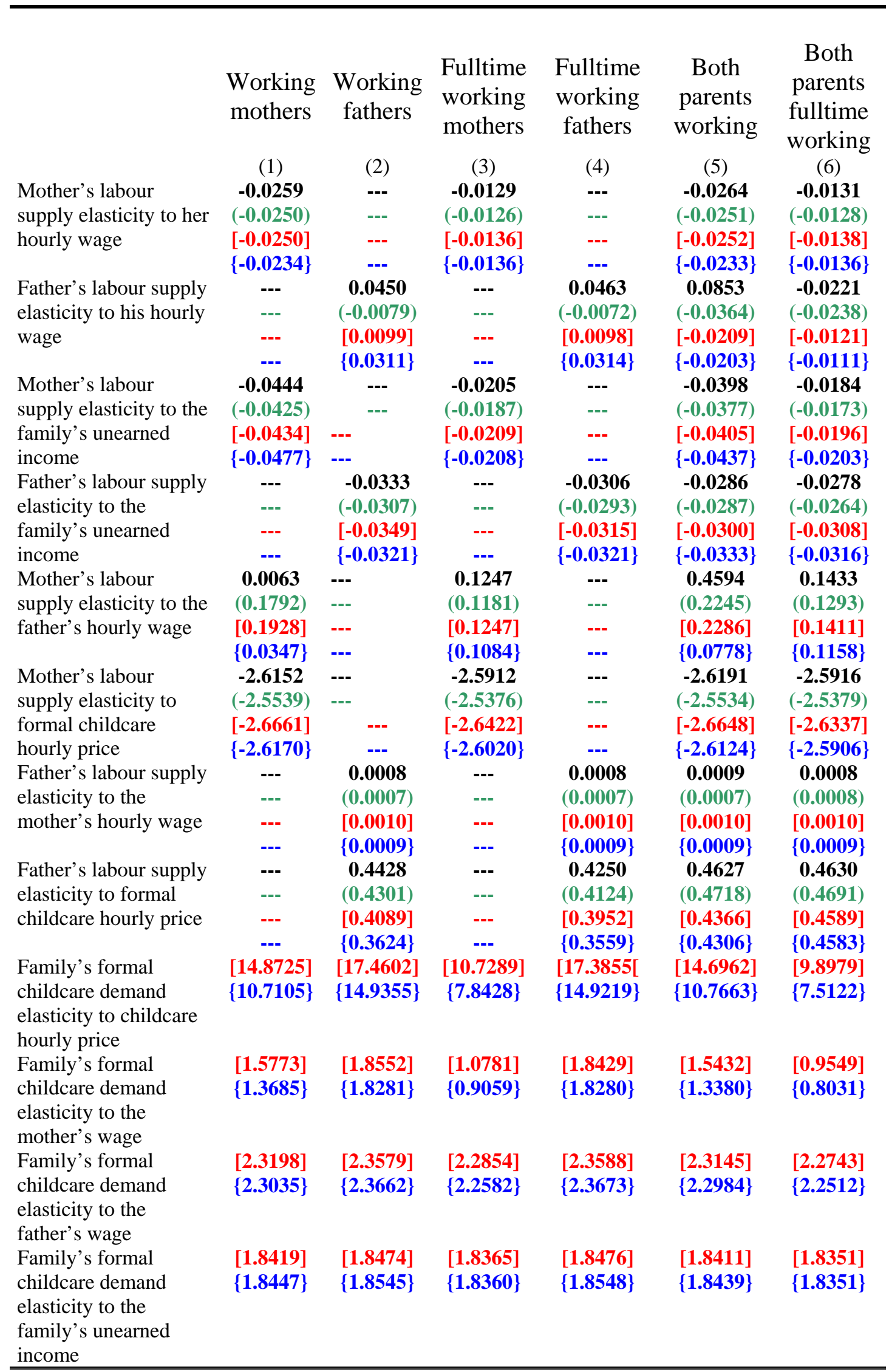

Source: General Household Survey 1991/92 Edition. No parentheses is whole sample; sub-sample of families with ( ) children aged under three; [ ] families using formal childcare; \{\} with children aged under three and using formal childcare 